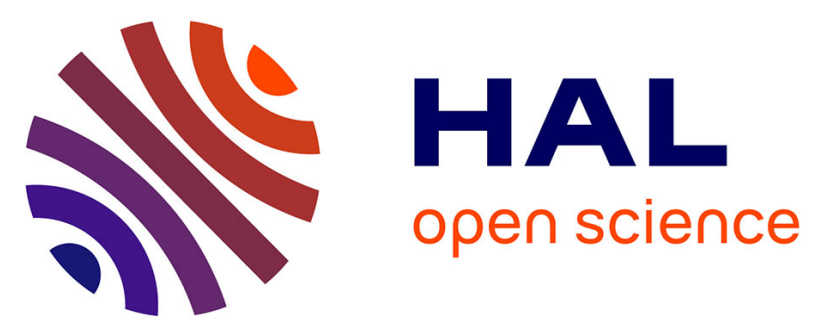

\title{
Gaseous carbonyls in China's atmosphere: Tempo-spatial distributions, sources, photochemical formation, and impact on air quality
}

Yingnan Zhang, Likun Xue, Can Dong, Tao Wang, Abdelwahid S Mellouki, Qingzhu Zhang, Wenxing Wang

\section{To cite this version:}

Yingnan Zhang, Likun Xue, Can Dong, Tao Wang, Abdelwahid S Mellouki, et al.. Gaseous carbonyls in China's atmosphere: Tempo-spatial distributions, sources, photochemical formation, and impact on air quality. Atmospheric Environment, 2019, 214, pp.116863. 10.1016/j.atmosenv.2019.116863 . insu-02263523

\section{HAL Id: insu-02263523 \\ https://hal-insu.archives-ouvertes.fr/insu-02263523}

Submitted on 5 Aug 2019

HAL is a multi-disciplinary open access archive for the deposit and dissemination of scientific research documents, whether they are published or not. The documents may come from teaching and research institutions in France or abroad, or from public or private research centers.
L'archive ouverte pluridisciplinaire HAL, est destinée au dépôt et à la diffusion de documents scientifiques de niveau recherche, publiés ou non, émanant des établissements d'enseignement et de recherche français ou étrangers, des laboratoires publics ou privés.

\section{(ㅇ)(1) $\$$}

Distributed under a Creative Commons Attribution - NonCommercial - NoDerivatives| 4.0 


\title{
Gaseous carbonyls in China's atmosphere: tempo-spatial distributions, sources, photochemical formation, and impact on air quality
}

Yingnan Zhang ${ }^{1}$, Likun Xue ${ }^{1 *}$, Can Dong ${ }^{1}$, Tao Wang ${ }^{2}$, Abdelwahid Mellouki ${ }^{1,3}$, Qingzhu Zhang ${ }^{1}$, Wenxing Wang ${ }^{1}$

${ }^{1}$ Environment Research Institute, Shandong University, Ji'nan, Shandong, China

${ }^{2}$ Department of Civil and Environmental Engineering, Hong Kong Polytechnic University, Hung Hom, Kowloon, Hong Kong, China

${ }^{3}$ ICARE/OSUC, CNRS, 45071 Orléans, France

Correspondence to Likun Xue (xuelikun@sdu.edu.cn)

\begin{abstract}
Carbonyls are an important class of oxygenated volatile organic compounds that play a crucial role in tropospheric chemistry as intermediates in the formation of ozone $\left(\mathrm{O}_{3}\right)$ and secondary organic aerosols. Over the last two decades, China's severe air pollution has led atmospheric chemists to devote substantial efforts to investigate the contribution of carbonyl compounds to the observed phenomena. This study reviews the major findings with regard to the gas-phase atmospheric chemistry of carbonyls in China, including their chemical compositions, temporal and spatial distributions, source apportionments, photochemical formation mechanisms, and impact on tropospheric oxidative capacity, air quality, and human health. Extremely high levels of carbonyls have frequently been observed in China's most rapidly developing regions, such as the North China Plain, the Yangtze River Delta, and the Pearl River Delta, but observational data from other regions are relatively scarce. Primary emissions and photochemical formation are major sources of carbonyls. Alkenes, aromatics, and isoprene have been identified as major precursors on a national scale. In addition, an increasing number of studies has focused on the effects of carbonyls on $\mathrm{O}_{3}$ formation, radical chemistry, the formation of secondary organic aerosols, and human health. The photolysis of oxygenated volatile organic compounds was recognized as a dominant pathway to ROx production, which further influences $\mathrm{O}_{3}$ formation, mainly via $\mathrm{HO}_{2}+\mathrm{NO}$ or $\mathrm{RO}_{2}+\mathrm{NO}$. Dicarbonyls (such as glyoxal and methylglyoxal) make important contributions to secondary organic aerosol formation via irreversible uptake by aqueous particles. Indoor and outdoor carbonyls often pose a significant threat to human health. This review also includes recommendations from the perspective of emissions, observations, photochemical formation mechanisms, and the effects of carbonyls to guide future research and provide scientific support for the formulation of mitigation policies to address photochemical air pollution.
\end{abstract}

Key words: Carbonyls; Human health; Ozone; Photochemical formation; Secondary organic aerosol 


\section{Introduction}

Carbonyls are important members of the family of oxygenated volatile organic compounds (OVOCs), which have a significant influence on the formation of ozone $\left(\mathrm{O}_{3}\right)$ and secondary organic aerosol (SOA) and hence play key roles in tropospheric chemistry (Calvert et al., 2011; Mellouki et al., 2015; Shen et al., 2013; and references therein). In recent decades, photochemical air pollution, characterized by high concentrations of $\mathrm{O}_{3}$ and other secondary contaminants, has become a major environmental concern in China due to its rapid urbanization and industrialization (Xue et al., 2014; Wang et al., 2017b; and references therein). Due to the significance of carbonyls in $\mathrm{O}_{3}$ formation, investigation of their pollution characteristics, sources, relationships with precursors, and impact on air quality is essential to better understand and control photochemical pollution.

Extensive studies have been conducted in the United States and Europe to investigate the pollution characteristics and formation mechanisms of photochemical smog since the mid-20th century. In contrast, only in the last three decades has China realized the severity of its photochemical air pollution, and finding solutions to photochemical pollution problems has become a top priority. Most studies have focused on the characteristics and formation mechanisms of surface $\mathrm{O}_{3}$ because it is regarded as the principal constituent of photochemical smog (Wang et al., 2017b; and references therein). In the lower troposphere, $\mathrm{O}_{3}$ is formed mainly via photochemical reactions that involve volatile organic compounds (VOCs) and nitrogen oxides (NOx) (Atkinson, 2000; Atkinson and Arey, 2003). Among these precursors, the pollution characteristics of hydrocarbons have rapidly attracted considerable attention because of their complexity and our poor understanding of them. More and more studies have focused on the sources and photochemistry of VOCs (e.g., Guo et al., 2006; Guo et al., 2004b; Xue et al., 2013). In particular, carbonyls have been dissected from VOCs as a research hotspot due to their great reactivity and important contributions to the formation of $\mathrm{O}_{3}$ and aerosols.

Despite its late start, China has made some promising progress in gaseous carbonyls research. In particular, in the last 20 years, several field observations have been carried out across China, and more than 25 carbonyl species have been monitored. Basic information on major carbonyls is provided in Table 1. The collected data show that various aspects of carbonyls have been investigated. Analyses of the temporal and spatial distributions of carbonyls have been widely performed (Cheng et al., 2014; Dai et al., 2012; Guo et al., 2016; Ho et al., 2014a; Ho et al., 2015; Ho et al., 2002; Lui et al., 2017a; Lui et al., 2017c; Pang and Lee, 2010; Pang and Mu, 2006), but few studies have focused on the sources or photochemical mechanisms of carbonyls, or their influence on atmospheric chemistry, air quality, and human health (Ling et al., 2017; Liu et al., 2009; Wang et al., 2017a; Xue et al., 2016; Yang et al., 2018), so these aspects are relatively poorly understood. In addition, most studies have focused on the characteristics of gaseous carbonyls; observational data on high-molecular weight carbonyls are relatively scarce. High-molecular weight carbonyls are semivolatile and largely partitioned into the particle phase, and their gas-phase concentrations are generally very low. This review article focuses on the most abundant gas-phase carbonyl compounds. Considering recent advances and the underlined needs, a critical review of the atmospheric chemistry of gaseous carbonyls in China's prevailing conditions is timely. 
In this review, we summarize the main findings of studies of gaseous carbonyl compounds in China and provide suggestions for future research. Section 2 briefly reviews the atmospheric chemistry of carbonyls, Section 3 summarizes field studies on and techniques for measuring carbonyls across China, and Section 4 presents the chemical compositions and tempo-spatial variations of carbonyls. Section 5 presents the source apportionment results and contributions of various sources to ambient carbonyls in various regions, and Section 6 summarizes the photochemical formation mechanisms of several major carbonyl species based on numerical modeling studies. Section 7 reviews assessments of the effects of carbonyls on $\mathrm{O}_{3}$ formation, atmospheric oxidizing capacity, SOA formation, and human health, and Section 8 summarizes the current findings and gives recommendations for future studies. Overall, this review aims to comprehensively summarize the current understanding of atmospheric carbonyls pollution in China, which should help to enlighten future research and aid in the formulation of control strategies to address regional air pollution.

\section{Brief review of atmospheric chemistry of carbonyls}

Carbonyls are organic molecules that contain at least a carbonyl group $(\mathrm{C}=\mathrm{O})$, and mainly include aldehydes and ketones. The chemical fates of carbonyls in the atmosphere are determined in large part by their structures and physical properties. For a given carbon number, carbonyls usually have lower vapor pressure than the corresponding parent alkanes, indicating the more polar nature of carbonyls. In addition, most carbonyls have low Henry's law constants, below $10^{3} \mathrm{M} \mathrm{atm}^{-1}$, so their physical removal (including wet and dry deposition) is not important (Calvert et al., 2011; Mellouki et al., 2015). Notable exceptions, including glyoxal (GLY) and methylglyoxal (MGLY), are extremely water-soluble and can easily hydrate and polymerize even at low humidity, hence contributing to SOA formation (Shen et al., 2013; and references therein). Owing to their distinctive structures and physical properties, carbonyls play an active role in tropospheric chemistry.

Figure 1 illustrates the major atmospheric chemical processes of carbonyls, including their sources and sinks. The sources of carbonyl species in the troposphere are classified as primary or secondary. Carbonyls can be emitted directly from sources such as vehicular emissions, biomass burning, industrial activities, and biogenic emissions (Guenther et al. 2012; Ho et al., 2007; Ma et al., 2016; Mason et al., 2001; Zhang et al., 2016). Secondary carbonyls are formed via the photochemical oxidation of VOCs, mainly via $\mathrm{RO}+\mathrm{O}_{2}$ reactions (Yang et al., 2018). Specifically, in the presence of sunlight, the OH-initiated degradation of VOCs leads to the production of alkyl peroxy radicals $\left(\mathrm{RO}_{2}\right)$, which then rapidly oxidize $\mathrm{NO}$ into $\mathrm{NO}_{2}$ and form RO radicals (Atkinson and Arey, 2003; Seco et al., 2007). Carbonyls can then be formed by reactions of $\mathrm{RO}+\mathrm{O}_{2}$. From the perspective of sources, OVOCs are important intermediate products that are formed during radical recycling circles. OVOCs also play significant roles in the radical-initiation processes because the photolysis of OVOCs presents a significant primary source of radicals in the atmosphere (Xue et al., 2016).

The most important loss pathways of carbonyls are photolysis and reactions with $\mathrm{OH}$ radicals. As mentioned above, the photolysis of carbonyls has been shown to make an important contribution to the primary production of $\mathrm{HO}_{2}$ and $\mathrm{RO}_{2}$ radicals (Jia et al., 2018; Li et al., 2018; Liu et al., 2012a; Xue et al., 2016; Xue et al., 2013). These radicals then participate in the NOx 
chemical cycle, oxidizing $\mathrm{NO}$ to $\mathrm{NO}_{2}$ and thus affecting $\mathrm{O}_{3}$ formation (Wang et al., 2018). The oxidation of carbonyls by $\mathrm{OH}$ forms an acyl peroxy radical (generally for aldehydes) or an alkyl peroxy radical (mainly for ketones), both of which then undergo radical recycling and termination as $\mathrm{RO}_{2}$. The heterogeneous loss of aqueous particles, which commonly occurs for dicarbonyls such as GLY and MGLY, also serves as an important sink of carbonyls (Fu et al., 2008; Hu et al., 2017; Li et al., 2013a). When these two dicarbonyls are in contact with aqueous particles and cloud droplets, SOA is rapidly produced. Another loss pathway of carbonyls is reaction with $\mathrm{O}_{3} / \mathrm{NO}_{3}$, which is an important fate of unsaturated carbonyls. Studies have shown that the dominant sources and sinks may vary between regions and carbonyl species.

\section{Field observations over China}

Field studies of carbonyls began relatively late in China. Tables S1-S4 list the field observations collected from articles published between 2000 and 2018. Although these references may not be exhaustive, we believe that they are sufficiently comprehensive to reflect the situation of carbonyls pollution in China. The measurement campaigns have been concentrated in the rapidly developing regions of the North China Plain (NCP), the Yangtze River Delta (YRD), and the Pearl River Delta (PRD). Extremely high levels of carbonyls, indicating severe carbonyls pollution, have been frequently observed (Figures $2 \mathrm{a}-\mathrm{d}$ ) due to the thriving industry and high population density. In contrast, limited efforts have been devoted to slow-developing areas.

In the late 1990s, measurement campaigns were conducted in urban Qingdao, a coastal city on the NCP. Tan et al. (2002) analyzed the seasonal variations in 11 aldehydes and ketones, explored their interrelationships, and qualitatively identified their sources. The increasing number of field studies conducted across China over the next 20 years identified more than 25 carbonyl species. Moreover, the number of field studies has drastically increased in the NCP and PRD regions since 2005, especially in 2008 for the purpose of controlling air pollution and preparing to host the Beijing Olympic Games. Note that these field observations were not limited to urban areas; they were conducted in various environments, including suburban, rural, mountain, and forest sites, to investigate the spatial distribution of carbonyls across China. Carbonyls levels were generally higher in urban sites (Cheng et al., 2014; Lui et al., 2017c; Yuan et al., 2012a). In addition, some field observations were conducted to examine the influence of various meteorological factors (e.g., haze, a lack of haze, dust storms, wind, and wet precipitation) on carbonyls levels (Duan et al., 2012; Pang et al., 2009a; Zhang et al., 2014). Other aspects, such as emission factors, have also been investigated. For example, to measure the on-road vehicle emissions of carbonyls, Ho et al. (2007) and Zhang et al. (2016) carried out measurements in tunnels in Hong Kong and Guangzhou, respectively. However, such investigations are relatively scarce in China.

Tables S1-S4 also show the measurement methods and analysis techniques used in each observational campaign. The various techniques used to measure and analyze carbonyls can be classified into two categories: online and offline. Offline methods were especially widely adopted during the measurement campaigns conducted before 2006. For example, many studies used silica cartridges coated with 2,4-dinitrophenylhydrazine (DNPH) to collect air samples for high-performance liquid chromatography (HPLC) analysis (Lü et al., 2010; Pang and Mu, 
2006; Wang et al., 2007). Although the DNPH-HPLC method has been widely used, its limitations include poor sensitivity and a strong dependence on the relative humidity (Pang et al., 2011). Some alternative offline approaches have been also developed. Altemose et al. (2015) used dansylhydrazine to derivatize carbonyls followed by HPLC analysis. Several other derivatization agents such as O-(2,3,4,5,6-pentafluorobenzyl)-hydroxylamine and pentafluorophenyl hydrazine have also been used to absorb carbonyls, followed by analysis with thermal desorption-gas chromatography-mass spectrometry (Ho and Yu, 2002, 2004; Pang et al., 2011). Szuleiko and Kim (2015) summarized commonly used derivatization agents and analytical methods for carbonyls analysis and indicated that DNPH-HPLC remains the most common choice among the offline methods mentioned above. Since 2006, differential optical absorption spectroscopy has been used to measure carbonyls (Kawamura et al., 2013; Ling et al., 2017; Nan et al., 2017), and Kawamura et al. (2013) compared the performances of multi-axis differential optical absorption spectroscopy and filter sampling-gas chromatography measurements. In addition, Shao et al. (2009) used gas chromatography-flame ionization detection-mass spectrometry (MS) to achieve the continuous monitoring of carbonyls in China at a high time resolution. Online methods such as proton transfer reaction-mass spectrometry (PTR-MS; including PTR-QMS, PTR-IT-MS, PTR-TOF-MS, PTR-TOF-CIMS, and PTR-IDCIMS) were then successively applied (Kanaya et al., 2009; Ma et al., 2016; Yuan et al., 2017; Yuan et al., 2016). Detailed information on these online methods has been published elsewhere (Chi et al., 2007; Cui et al., 2016; Ho and Yu, 2004; Inomata et al., 2008; Wang et al., 2014b). Although offline methods have been widely used, they have some disadvantages. One disadvantage is that the length of the derivatization time makes it difficult to characterize the continuous evolution process of carbonyls. The application of online methods has achieved continuous online measurements of carbonyls in the atmosphere at the trace level. Nevertheless, some carbonyl species still cannot be detected with these novel methods (Chen et al., 2014; Kawamura et al., 2013; Nan et al. 2017; Wang et al., 2014b). For example, PTR-MS can only detect species with a proton affinity greater than that of water and cannot distinguish isomeric/isobaric compounds (Blake et al., 2009; Yuan et al., 2017). Formaldehyde and acetaldehyde cannot be detected with online gas chromatography-MS because they do not produce unique ions in the MS (Pang et al., 2011). Further developments in measurement techniques for carbonyls are required to provide high-quality data and cover more species in future studies.

It is noteworthy to mention that most of these field observations were carried out by the research community and that carbonyls have not been listed as a target by the national air quality monitoring network. Very recently, Chinese government agencies have begun to attach greater importance to the measurement of carbonyls after realizing their significance in ozone pollution. In 2017, the Ministry of Ecology and Environment of the People's Republic of China issued a series of regulations to promote the development of OVOC measurement, including both manual and automatic monitoring (http://www.mee.gov.cn/). For example, some air quality monitoring stations in key regions and/or cities have been asked to perform routine measurements of 13 major carbonyls (see Table 1) with the same method (i.e., DNPH-HPLC and gas chromatography-flame ionization detection-MS), so a picture of nationwide carbonyls levels across China seems around the corner. 


\section{Chemical compositions and tempo-spatial distributions}

Historical data show that formaldehyde $(\mathrm{HCHO})$, acetaldehyde $\left(\mathrm{CH}_{3} \mathrm{CHO}\right)$, and acetone $\left(\mathrm{CH}_{3} \mathrm{COCH}_{3}\right)$ are the three most abundant carbonyl species in field studies, but the most abundant species vary between sites. The contributions of these three species to the total observed carbonyl compounds generally exceed 70\% (Guo et al., 2014a; Guo et al., 2016; Yang et al., 2017). In addition, the mixing ratios of two dicarbonyl compounds (i.e., GLY and MGLY) that are crucial players in the formation of $\mathrm{O}_{3}$ and $\mathrm{SOA}$ have also shown high concentration levels in China (Ho et al., 2014a; Rao et al., 2016).

Figures 2a-d show the spatial distributions of major carbonyl species over China. Carbonyls pollution is obviously much more severe in the NCP, YRD, and PRD regions than in other areas. Of these three severely polluted regions, the PRD has a slightly better carbonyls pollution situation. Within a given region, higher levels of carbonyls were usually observed at urban sites than at suburban and rural sites. Megacities such as Beijing, Shanghai, Guangzhou, and Hong Kong have severe carbonyls pollution. High levels of HCHO (exceeding $20 \mathrm{ppbv}$ ), $\mathrm{CH}_{3} \mathrm{CHO}$ (exceeding $10 \mathrm{ppbv}$ ), and $\mathrm{CH}_{3} \mathrm{COCH}_{3}$ (exceeding $6 \mathrm{ppbv}$ ) have been frequently observed in Beijing (Altemose et al., 2015; Duan et al., 2008; He et al., 2016; Pang and Mu, 2006). Observational data for carbonyls other than the top three carbonyl species are relatively limited because they have high reactivities and low concentration levels. Nevertheless, observational data for propionaldehyde $\left(\mathrm{C}_{2} \mathrm{H}_{5} \mathrm{CHO}\right)$, butyraldehyde $\left(\mathrm{C}_{3} \mathrm{H}_{7} \mathrm{CHO}\right)$, GLY, and MGLY have also been collected. The spatial distributions of these four carbonyl species differ slightly from those of the three abundant species. In addition to the NCP, YRD, and PRD regions, Taiwan also showed elevated levels of $\mathrm{C}_{2} \mathrm{H}_{5} \mathrm{CHO}(>1 \mathrm{ppbv})$ and $\mathrm{C}_{3} \mathrm{H}_{7} \mathrm{CHO}(>2 \mathrm{ppbv})$ (Huang et al., 2008; Lü et al., 2010; Lü et al., 2009; Shi et al., 2011; Wang et al., 2010a). Figures 3a-b show that GLY and MGLY in limited studies were found to exhibit high levels in Beijing and Xi' an ( $>0.3$ ppbv and $>1$ ppbv for GLY and MGLY, respectively) (Ho et al., 2014a; Rao et al., 2016). GLY generally has a greater concentration than MGLY due to its longer lifespan (2.9 vs. $1.6 \mathrm{~h}$ ) (Fu et al., 2008). Dai et al. (2012) reported similar data in which the GLY concentrations were higher than those of MGLY in Xi' an in winter. However, at the same site, MGLY exhibited higher levels than GLY during summer, which may be attributed to seasonal variations in the sources of dicarbonyls.

The status of carbonyls pollution in China is less optimal than that of other countries. For example, levels of major carbonyl species $\left(\mathrm{HCHO}+\mathrm{CH}_{3} \mathrm{CHO}+\mathrm{CH}_{3} \mathrm{COCH}_{3}\right)$ exceeding $20 \mathrm{ppbv}$ have frequently been observed in Beijing (e.g., Duan et al., 2012; Duan et al., 2008; He et al., 2016; Pang and Mu., 2006; Rao et al., 2016; Yang et al., 2018), on par with those of Los Angeles (19.2 ppbv in 2008-2010) (Warneke et al., 2012) and Campeche, Mexico (37.1 ppbv in the summer of 2004) (Cerón et al., 2007), which have experienced the world's most serious photochemical pollution.

Four year-round observation campaigns are carefully selected to elucidate the seasonal variations in carbonyls in various regions (Huang et al., 2008; Lü et al., 2010; Lui et al., 2017c; Pang and $\mathrm{Mu}, 2006$ ). These four measurements were conducted in urban areas of Beijing (from November 2004 to October 2005), Shanghai (from January to October 2007), Guangzhou (from January to November 2005), and Hong Kong (from January to December 2013), 
respectively. These studies were chosen to obtain a comprehensive understanding of the severe carbonyls pollution characteristics in typical fast-developing regions of China. Although a time gap separates these four observation campaigns, we believe that it should have little effect on the seasonal variations of carbonyls. Figure 4 shows that $\mathrm{HCHO}$ and $\mathrm{CH}_{3} \mathrm{CHO}$ were significantly more abundant in summer than in winter in Beijing, Shanghai, and Guangzhou. This difference can be explained by the stronger photochemical activities in summer and was confirmed with ${ }^{13} \mathrm{C}$ isotope evidence by Guo and Chen (2013). In Hong Kong, both HCHO and $\mathrm{CH}_{3} \mathrm{CHO}$ exhibited their maximum levels in autumn, and similar levels were seen in summer and winter. The reason for this distinct seasonal pattern is that Hong Kong is frequently influenced by clean marine air masses under prevailing southerly or southeasterly winds in summer, which alleviates carbonyls pollution to some degree. Autumn is the most photochemically polluted season in Hong Kong due to the regional transport of continental air masses from mainland China via the winter monsoon and the sunny weather at low latitudes (Wang et al., 2009b). Another exception is the seasonal pattern in Xiamen, where higher levels of both $\mathrm{HCHO}$ and $\mathrm{CH}_{3} \mathrm{CHO}$ were found in winter than in summer, which may be attributed to the stronger sea-land breeze circulation during summer (Ho et al., 2015).

The diurnal patterns in carbonyls levels have been also examined. Liu et al. (2015) reported the diurnal patterns of several carbonyl species measured at PKU in urban Beijing in July 2008. Levels of $\mathrm{HCHO}, \mathrm{CH}_{3} \mathrm{CHO}$, and $\mathrm{CH}_{3} \mathrm{COCH}_{3}$ peaked at noon after a daytime buildup, following the trend of $\mathrm{O}_{3}$, thus indicating the significance of secondary production during the day. These carbonyl species then reached another peak in early evening, which may be attributed to primary vehicle emissions. At Mount Tai, Yang et al. (2017) observed an evening peak in carbonyls that could be ascribed to regional transport. In addition, diurnal variations in carbonyls in some studies are not clear-cut (Cheng et al., 2014; Guo et al., 2014a; Guo et al., 2016; Huang et al., 2008; Lü et al., 2010; Rao et al., 2016; Yuan et al., 2012b). In general, the mixing ratios of carbonyls are related to many factors, including their sources (both primary emissions and secondary formation), sinks, regional transport, and meteorological conditions. Seasonal variations and diurnal patterns roughly reflect the influences of these factors on the ambient carbonyls levels.

\section{Source apportionment}

The sources of carbonyls are rather complex. Several methods have been used to diagnose or quantify the major sources of ambient carbonyls, and detailed information on these methods can be found in the Supplementary Materials. Here, we focus on the major findings of the source apportionment studies in a few regions.

\subsection{North China Plain}

Many studies have attempted to identify the principal sources of carbonyls and quantify their contributions to ambient carbonyls levels in the NCP. Although various methods have been used, source apportionment results have consistently demonstrated the dominance of the secondary formation of carbonyls in summer. For example, Pang and $\mathrm{Mu}$ (2006) conducted an intensive measurement campaign from November 2004 to October 2005 in urban Beijing and found a strong correlation between carbonyls and $\mathrm{O}_{3}$ in summer. In addition, the calculated $\mathrm{C}_{1} / \mathrm{C}_{2}$ ratios exhibited the highest average values (e.g., 1.94) in summer, which suggests the 
importance of photo-oxidation of biogenic hydrocarbons. Later, during the summer of 2014, Yang et al. (2017) used the multilinear regression method and found that secondary formation made the largest contribution to the carbonyls level (except $\mathrm{CH}_{3} \mathrm{COCH}_{3}$ ) at Mount Tai, a regional site in the central NCP. Liu et al. (2009) used the photochemical age-based parameterization method and found that nearly half of the $\mathrm{CH}_{3} \mathrm{CHO}, \mathrm{C}_{2} \mathrm{H}_{5} \mathrm{CHO}$, and $\mathrm{C}_{3} \mathrm{H}_{7} \mathrm{CHO}$ in urban Beijing were attributed to secondary anthropogenic sources, whereas the measured alcohols $\left(\mathrm{CH}_{3} \mathrm{OH}\right.$ and $\left.\mathrm{C}_{2} \mathrm{H}_{5} \mathrm{OH}\right)$ and ketones $\left(\mathrm{CH}_{3} \mathrm{COCH}_{3}\right.$ and $\mathrm{CH}_{3} \mathrm{COC}_{2} \mathrm{H}_{5}$ [methyl ethyl ketone]) were mainly from primary sources. Secondary formation usually made a larger contribution to reactive aldehydes than to inert alcohols and ketones. This conclusion was also confirmed by Yuan et al. (2012b), who also reported that biogenic VOCs accounted for a large part $(36 \%)$ of $\mathrm{HCHO}$ formation at PKU in urban Beijing. In contrast, Chen et al. (2014) identified a much lower contribution of biogenic sources to HCHO at the same site based on the results of a positive matrix factorization model. The cause of this discrepancy may be that the biogenic sources identified by the positive matrix factorization model represented relatively fresh emissions, whereas secondary formation from biogenic sources was also considered by Yuan et al. (2012b).

In comparison, carbonyls were reported to come mainly from primary anthropogenic emissions in winter, when the photochemistry is relatively weak (Ho et al., 2015; Pang and $\mathrm{Mu}$, 2006). In winter 2004, Pang and Mu (2006) found a significant correlation between carbonyls and $\mathrm{CO}$, an anthropogenic emission tracer, over urban Beijing, thus suggesting the importance of anthropogenic emissions (especially vehicular emissions) to carbonyls levels. Furthermore, the results of principal component analysis showed that gasoline and diesel engine exhausts are the principal components of vehicle emissions, which make an important contribution to ambient carbonyls (Rao et al., 2016). However, Chen et al. (2014) found that secondary formation dominated carbonyls sources not only in summer (with a contribution of $46.0 \%$ ), but also in winter (with a contribution of 51.2\%). In addition, coal burning for heat during winter was identified as an important component of primary anthropogenic emissions (Chen et al., 2014).

\subsection{Yangtze River Delta}

Source apportionment studies in the YRD region are relatively limited compared to those in the NCP and PRD regions. In the YRD region, primary emissions were identified as important sources of carbonyls in spring and autumn. Huang et al. (2009) reported that the ambient carbonyls in urban Shanghai in April 2008 were dominated by vehicle emissions during the day and industrial emissions at night. The importance of industrial emissions was also confirmed by Ma et al. (2016), who used a multilinear regression approach to show that industrial activities made the largest contribution (59\%) to HCHO in April 2015 in an industrial zone of Zhejiang province. In contrast, Wang et al. (2015) used the same method and found that industrial emissions made a relatively smaller contribution $(19 \%)$ to $\mathrm{HCHO}$ at a rural site in Nanjing, Jiangsu province; $\mathrm{CH}_{3} \mathrm{CHO}$ and $\mathrm{CH}_{3} \mathrm{COCH}_{3}$ dominated ( $>50 \%$ ). These results prove the variability of carbonyls sources in various parts of the YRD region. One point in common is that the contribution of photochemical formation to carbonyls was relatively low in both studies due to weaker photochemical reactions during spring and autumn in the YRD 
region.

\subsection{Pearl River Delta}

Severe photochemical smog episodes are frequently observed in the PRD region during autumn because of its distinct meteorological conditions. Intensive measurement campaigns were conducted from September to November 2010 at a mountain site (TMS) and an urban site (TW) in Hong Kong (Guo et al., 2013; Ling et al., 2016). The positive matrix factorization model results were similar at these two sites. Secondary formation (including in-situ photochemical production and the transport of secondary products) was identified as the major contributor to $\mathrm{HCHO}(>50 \%)$ and $\mathrm{CH}_{3} \mathrm{CHO}(>45 \%)$. Meanwhile, secondary formation and vehicle emissions made the greatest contribution $(>65 \%)$ to the ambient $\mathrm{CH}_{3} \mathrm{COCH}_{3}$ level. These findings indicate the importance of photochemical formation. In addition, carbonyls were more likely to be primary emissions in urban areas than in rural areas, as confirmed by Lui et al. (2017c). In addition to autumn, Ling et al. (2017) showed strong photochemical activities in summer, but the prevailing southerly and southeasterly winds from the oceans alleviated carbonyls pollution during summer, whereas the northeasterly winds in autumn aggravated the pollution. Wang et al. (2017a) investigated the source category contributions to HCHO in different seasons. They used the photochemical age-based parameterization method and found that the contributions of biogenic sources (including both primary and secondary biogenic sources) to HCHO were much higher during summer (41\%) and autumn (39\%) than during spring (26\%) and winter (28\%). In contrast, the contributions of primary anthropogenic emissions during spring (20\%) and winter (18\%) were double those during summer $(9 \%)$ and autumn (9\%).

Some studies also identified primary emissions as important sources of carbonyls (Feng et al., 2005; Guo et al., 2004a; Ho et al., 2002; Lü et al., 2009; Yuan et al., 2010), so the emission profiles of vehicular emissions and biomass burning were investigated in the PRD region. Two tunnel tests were successively conducted in Hong Kong and Guangzhou (Ho et al., 2007; Zhang et al., 2016). Ho et al. (2007) reported a range of 21.7 to $68.9 \mathrm{mg} \mathrm{veh}^{-1} \mathrm{~km}^{-1}$ of emission factors of a combination of 15 monocarbonyls. Furthermore, HCHO presented the highest emission factor throughout the sampling period, followed by $\mathrm{CH}_{3} \mathrm{CHO}$ and $\mathrm{CH}_{3} \mathrm{COCH}_{3}$ (Ho et al., 2012). Higher emission factors of carbonyls were observed in summer than in winter, partly due to the higher temperature. Zhang et al. (2016) reported average emission factors of 1.18 and $0.52 \mathrm{mg}$ $\mathrm{veh}^{-1} \mathrm{~km}^{-1}$ for GLY and MGLY, respectively. The higher emission factor of GLY usually accompanies a higher proportion of gasoline vehicles, whereas a higher proportion of diesel vehicles was responsible for the higher emission factors of monocarbonyls and MGLY. In addition, biomass burning was also found to exert a significant influence on ambient carbonyls in specific circumstances. Wang et al. (2016) suggested that biomass burning could serve as a primary source of OVOCs and promote the production of secondary OVOCs by emitting their precursors. Yuan et al. (2010) reported an enhancement of $10 \%$ to $18 \%$ of OVOCs during biomass burning plumes at a receptor site in the PRD region. Yuan et al. (2013) and Mo et al. (2016) both reported that OVOC emissions were significantly underestimated in the current emission inventory, possibly due to the poor understanding of the emission characteristics of nonvehicle primary sources. In addition to anthropogenic emissions, some studies have 
reported biogenic emissions of carbonyls. In China, the total biogenic VOC emissions were reported to range from 35 to $50 \mathrm{Tg} / \mathrm{y}$ from 1981 to 2003, among which the contributions of OVOCs ranged from $30 \%$ to $40 \%$ ( $\mathrm{Li}$ and Xie, 2014). Moreover, Guenther et al. (2012) identified $\mathrm{CH}_{3} \mathrm{COCH}_{3}(43.7 \mathrm{Tg} / \mathrm{y}), \mathrm{CH}_{3} \mathrm{CHO}(20.7 \mathrm{Tg} / \mathrm{y})$, and $\mathrm{HCHO}(5.0 \mathrm{Tg} / \mathrm{y})$ as the three most abundant primary biogenic carbonyl species on a global scale. However, great uncertainty remains in the evaluation of biogenic carbonyls emissions.

As discussed above, secondary formation generally dominated the carbonyls sources in China, but the importance of the contributions from primary emissions should not be overlooked. However, current knowledge of carbonyls sources remains far from sufficient to provide scientific support for carbonyls abatement strategies. First, the means to accurately characterize primary emissions (both anthropogenic and biogenic) is a major work underway and is urgently needed to aid in compiling the current emission inventories. Second, the photochemical formation mechanisms of some reactive carbonyl species remain poorly understood, so more relevant studies are needed.

\section{Photochemical formation mechanisms}

The source apportionment results elucidate the necessity to comprehensively understand the secondary formation mechanisms of carbonyls. The methods commonly used to investigate the photochemical formation mechanisms of carbonyls are based on chemical models. Investigations have included monocarbonyls, among others. Important dicarbonyls such as GLY and MGLY are also involved. Below we summarize the major findings regarding the photochemical formation mechanisms of monocarbonyls and dicarbonyls.

\subsection{Monocarbonyls}

In China, the photochemical formation mechanisms of monocarbonyls such as $\mathrm{HCHO}$, $\mathrm{CH}_{3} \mathrm{CHO}, \mathrm{CH}_{3} \mathrm{COCH}_{3}$, and $\mathrm{CH}_{3} \mathrm{COC}_{2} \mathrm{H}_{5}$ have been investigated with an observation-based box model coupled with chemical mechanisms. Previous studies showed that models could well reproduce the diurnal variations and concentrations of secondary products such as $\mathrm{O}_{3}$, HCHO, and GLY (Li et al., 2014; Ling et al., 2017).

Li et al. (2014) and Ling et al. (2017) conducted field observations in the PRD region in July 2006 at a semirural site (BG) and an urban site (GPEMC), respectively, and further refined the secondary formation pathways of HCHO. Li et al. (2014) found that isoprene oxidation contributed most to the secondarily formed $\mathrm{HCHO}(43 \%)$, followed by oxidation of anthropogenic alkenes (29\%), aromatics (15\%), and alkanes (13\%). In contrast, Ling et al. (2017) showed that alkenes (including isoprene) made an overwhelming contribution (77\%) to the photochemical production of HCHO, followed by aromatics $(20 \%)$ and alkanes $(3 \%)$. Trans-2-butene was identified as the largest contributor (16\%) of the individual VOC precursors, whereas isoprene made a smaller contribution $(9.6 \%)$. The differences between the results of Li et al. (2014) and Ling et al. (2017) are likely the result of differences in the chemical compositions of first-generation VOC precursors between urban and rural areas. The photochemical formation mechanism of $\mathrm{CH}_{3} \mathrm{COCH}_{3}$ differs greatly from that of $\mathrm{HCHO}$. Guo et al. (2013) used the observation-based box model to investigate the photochemical precursors of $\mathrm{CH}_{3} \mathrm{COCH}_{3}$ from September to November 2010 at a mountain site (TMS) and an urban site 
(TW) in Hong Kong. $\mathrm{C}_{3}-\mathrm{C}_{6}$ alkanes were found to be the largest contributor to the secondary formation of $\mathrm{CH}_{3} \mathrm{COCH}_{3}$ at both sites, making an average contribution of $28.7 \%$ at TMS and $54.5 \%$ at TW. This result is also consistent with that of Jacob et al. (2002), who confirmed the oxidation of $\mathrm{C}_{3}-\mathrm{C}_{5}$ isoalkanes as a dominant source of the in situ formation of $\mathrm{CH}_{3} \mathrm{COCH}_{3}$ in the northern hemisphere. The contributions of $\mathrm{C}_{2}-\mathrm{C}_{3}$ alkenes to secondarily formed $\mathrm{CH}_{3} \mathrm{COCH}_{3}$ were comparable at the two sites $(20.0 \%$ at TMS and $16.1 \%$ at TW). Furthermore, the most important of all measured VOC precursors was identified to be i-butene at TMS and i-butane at TW, with the two compounds contributing $20 \%$ and $30 \%$, respectively.

In the NCP region, the relationships between monocarbonyls and their precursors were also investigated using box models. As mentioned above, many observation campaigns were carried out in 2008 to improve air quality and prepare for the Beijing Olympic Games. During that period, two intensive measurements conducted from July to August 2008 were selected for comparison. These two measurements were carried out by Liu et al. (2015) in the PKU and by Yang et al. (2018) at the Chinese Research Academy of Environmental Sciences (both in urban areas). These two studies investigated the photochemical formation mechanisms of carbonyls from different perspectives. Yang et al. (2018) identified five major pathways responsible for the formation of secondary $\mathrm{HCHO}$ and $\mathrm{CH}_{3} \mathrm{CHO}$ : OVOC photolysis, $\mathrm{O}_{3}+\mathrm{OVOCs}$, $\mathrm{OH}+\mathrm{OVOCs}$, radical propagation reactions, and $\mathrm{RO}+\mathrm{O}_{2}$ reactions. Of these, $\mathrm{RO}+\mathrm{O}_{2}$ reactions made the largest contribution to the in situ formation of $\mathrm{HCHO}(\sim 85 \%)$ and $\mathrm{CH}_{3} \mathrm{CHO}(\sim 70 \%)$. One point that must be clarified is that the target carbonyls were excluded from the OVOC precursors mentioned above. As for the first-generation VOC precursors, the further refinement of the $\mathrm{RO}+\mathrm{O}_{2}$ formation routes suggested that anthropogenic alkenes played an important role in the production of RO $(\sim 30 \%)$. Liu et al. (2015) investigated the photochemical formation mechanisms of carbonyls from the perspective of precursors and showed that anthropogenic alkenes made the largest contribution to the photochemical formation of $\mathrm{HCHO}(54 \%)$, $\mathrm{CH}_{3} \mathrm{CHO}(91 \%)$, and $\mathrm{CH}_{3} \mathrm{COCH}_{3}(60 \%)$, whereas alkanes were predominantly responsible for the in situ formation of $\mathrm{CH}_{3} \mathrm{COC}_{2} \mathrm{H}_{5}(>95 \%)$. As for individual VOC precursors, the oxidation of isoprene made the largest contribution (30\%) to secondary HCHO. In addition, the loss rates of $\mathrm{HCHO}$ were governed both by reactions with $\mathrm{OH}$ and by photolysis, whereas $\mathrm{CH}_{3} \mathrm{CHO}$ losses were dominated by reactions with $\mathrm{OH}$ (Yang et al., 2018). Such studies of the detailed photochemical processes of carbonyls remain limited in other regions, and more efforts are needed.

\subsection{Dicarbonyls}

The photochemical formation mechanisms of GLY and MGLY have also been investigated (Chan Miller et al., 2016; Liu et al., 2012b; Yang et al., 2018). Fu et al. (2008) conducted a detailed simulation based on a global three-dimensional model (GEOS-Chem) and found that isoprene dominated the secondary formation of GLY and MGLY on a global scale, whereas acetylene and acetone were the second most important precursors for GLY and MGLY, respectively. However, the photochemical formation mechanisms of GLY and MGLY in China differ significantly from those on a global scale. Liu et al. (2012b) quantified the missing source of GLY in China by comparing the vertical column densities observed by SCIAMACHY and those simulated by a three-dimensional regional chemical transport model. Inverse modeling 
was then applied to calculate the emission adjustment for each grid, and the results showed a substantial underestimation of aromatics emissions (by a factor of 4 to 10) in the VOC emission inventories over China, which well explained the missing source of GLY. Later, Chan Miller et al. (2016) identified the PRD region as a hotspot of GLY based on satellite observations from the Ozone Monitoring Instrument. In contrast with the results of Liu et al. (2012b), they found good agreement between the observed GLY enhancements and the current VOC emission inventories. The difference in the results was attributed to the combined effects of bias in the satellite data and underestimation of GLY production from aromatics oxidation. Based on MCM v3.2 (Master Chemical Mechanism, a nearly-explicit chemical mechanism), the aromatics emitted by industrial sources were determined as a dominant contributor to GLY formation in the PRD region (Chan Miller et al., 2016). Yang et al. (2018) investigated the photochemical formation mechanisms of GLY and MGLY in urban Beijing. $\mathrm{RO}+\mathrm{O}_{2}$ and $\mathrm{OH}+\mathrm{OVOCs}$ reactions were identified as the dominant formation pathways for both GLY and MGLY. Furthermore, aromatics made the largest contribution of all first-generation VOC precursors to the formation of GLY (>43\%) and MGLY (39\%). The dominant first-generation VOC precursors responsible for secondarily formed GLY and MGLY in Beijing are similar to those identified in the PRD region (i.e., aromatics).

Overall, some progress has been made in gaining a better understanding of the photochemical formation mechanisms of carbonyls in China. Nonetheless, most studies have focused on the identification of important precursors; the detailed photochemical processes of carbonyls have not been fully addressed. Moreover, most work has been concentrated in the NCP and PRD regions, with few studies considering other regions of China. More work is needed to further unravel the detailed formation mechanisms of carbonyls with a wider spatial coverage in China.

\section{Effects of carbonyls on atmospheric chemistry, air quality, and human health}

\subsection{Atmospheric oxidative capacity and radicals}

OVOCs play crucial roles in radical chemistry. First, they exert a significant influence on radical initiation reactions. As mentioned in Section 2, OVOC photolysis is acknowledged as a major primary source of ROx radicals. Xue et al. (2016) used box modeling analysis to quantify the radical budget of a prolonged severe photochemical smog episode in Hong Kong and found that OVOC photolysis (except for $\mathrm{HCHO}$ photolysis) made an overwhelming contribution (47\%) to daytime primary ROx production. Moreover, the photolysis of $\mathrm{HCHO}$ was an important source of $\mathrm{HO}_{2}$. The dominance of OVOC photolysis to $\mathrm{RO}_{2}+\mathrm{HO}_{2}$ production was also found in many other areas, such as Beijing, Lanzhou, and Waliguan (see Table 2 and references therein). Despite this similarity, $\mathrm{RO}_{2}+\mathrm{HO}_{2}$ production from OVOC photolysis was much more efficient in polluted urban areas than in rural or remote areas.

OVOCs also play an important role in radical recycling cycles, which further influence the atmospheric oxidizing capacity. Generally, $\mathrm{OH}$ is the largest contributor to the atmospheric oxidizing capacity. Some studies have calculated the $\mathrm{OH}$ reactivity to track the contributions of various VOC groups to $\mathrm{OH}$ oxidation. Table 2 summarizes the related studies of $\mathrm{OH}$ 
reactivity in China. In the PRD region, Lou et al. (2010) compared the measured and calculated $\mathrm{OH}$ reactivity and found a discrepancy of a factor of $\sim 2$. Further examination suggested that the missing reactivity was attributed to a lack of measurement data for OVOCs (mainly aldehydes and ketones), suggesting the significant contributions of carbonyls to $\mathrm{OH}$ reactivity. Yuan et al. (2012a) calculated that that $\mathrm{OH}$ reactivity was dominated by OVOCs. The dominance of OVOCs to $\mathrm{OH}$ reactivity in the PRD region was also confirmed by Xue et al. (2016) and Li et al. (2018) based on model simulations. In the NCP region, Yang et al. (2018) and Fuchs et al. (2017) reported the dominant contributions of OVOCs to $\mathrm{OH}$ reactivity. Of all OVOC species, $\mathrm{HCHO}$ and $\mathrm{CH}_{3} \mathrm{CHO}$ were identified as the largest contributors to $\mathrm{OH}$ reactivity (Duan et al., 2012; Fuchs et al., 2017; Shao et al., 2009; Yang et al., 2018). In addition, OVOCs (especially carbonyls) usually dominated $\mathrm{OH}$ reactivity in rural areas, whereas alkenes tended to dominate $\mathrm{OH}$ reactivity in urban areas. Overall, OVOCs not only behaved as a predominant radical source via photolysis but also as a major contributor to the atmospheric oxidizing capacity via $\mathrm{OH}$-initiated degradation.

\section{$7.2 \mathrm{O}_{3}$ formation}

The worsening $\mathrm{O}_{3}$ pollution situation has caused wide public concern, and many studies have investigated $\mathrm{O}_{3}$-precursor relationships (e.g., Duan et al., 2008; Tan et al., 2018; Wang et al., 2018; Xue et al., 2014; Xue et al., 2013). However, most studies have focused on hydrocarbons; relatively limited attention has been paid to the contributions of OVOCs to $\mathrm{O}_{3}$. A close relationship has been assumed to exist between $\mathrm{O}_{3}$ and OVOCs because high levels of $\mathrm{O}_{3}$ and OVOCs are often monitored concurrently during photochemical pollution episodes (Wang et al., 2018; Yang et al., 2017). A clear understanding of the role played by carbonyls during $\mathrm{O}_{3}$ formation is essential for air pollution control.

Based on the PBM-MCM model, Wang et al. (2018) found that HCHO photolysis dominated $\mathrm{HO}_{2}$ formation and that $\mathrm{HO}_{2}$ then further oxidizes $\mathrm{NO}$ to $\mathrm{NO}_{2}$, facilitating the formation of $\mathrm{O}_{3}$. Some studies evaluated the $\mathrm{O}_{3}$-precursor relationships based upon $\mathrm{O}_{3}$ formation potential (OFP) calculations and model sensitivity tests. Yuan et al. (2012a) calculated the OFP of various VOC groups measured in the PRD region and found that aromatics made the largest contribution to the OFP at most urban sites, whereas carbonyls usually dominated the OFP in rural areas. In contrast, Duan et al. (2008) found that carbonyls dominated the OFP (40\%) at an urban site in Beijing. This discrepancy reveals the different formation regimes of $\mathrm{O}_{3}$ in various regions of China. However, one common conclusion is that of the carbonyl species, $\mathrm{HCHO}$ and $\mathrm{CH}_{3} \mathrm{CHO}$ usually exhibited the highest OFP due to their relatively high reactivity and abundance. Some studies were based on model-calculated relative incremental reactivity. Yang et al. (2018) identified carbonyls as the most sensitive precursors responsible for $\mathrm{O}_{3}$ formation in Beijing. Wang et al. (2018) calculated the relative incremental reactivity values for each VOC precursor to $\mathrm{O}_{3}$ production over the South China Sea. They showed that $\mathrm{HCHO}$ exhibited the highest relative incremental reactivity value on both episode days and non-episode days (Here, the episode days refer to days with maximum hourly average $\mathrm{O}_{3}$ value exceeding 100 ppbv [China's Grade II Standard]). Cutting carbonyls emissions would be an effective way to alleviate $\mathrm{O}_{3}$ pollution in these regions.

The studies mentioned above have demonstrated that carbonyls make important 
contributions to $\mathrm{O}_{3}$ formation. These findings are useful for the formulation of effective ozone pollution control strategies. However, most of these studies have focused on the sensitivity of $\mathrm{O}_{3}$ formation to the bulk of carbonyls, to which secondary formation contributed a large proportion. Control policies can only reduce primary emissions. Thus, more efforts are needed to better quantify the contributions of primary carbonyl species to $\mathrm{O}_{3}$ formation in China.

\subsection{SOA formation}

Heterogeneous reactions are an important sink of carbonyls and an important source of SOA. As previously mentioned, GLY and MGLY usually exhibit high levels in China. These two small dicarbonyls have relatively high reactivity and water solubility (Shen et al., 2013; and references therein). They can easily hydrate and polymerize even at low humidity. This distinct feature makes GLY and MGLY important contributors to SOA formation. Fu et al. (2008) added the known sources and sinks of GLY and MGLY to the GEOS-Chem model and found that the yield of global SOA increased by $38 \%$, thus indicating their significant contributions to SOA formation on a global scale.

Investigations of the relationships between carbonyls and SOA formation in China are relatively limited. Yuan et al. (2013) reported a discrepancy between measured and calculated SOA and attributed it partly to the lack of measurement data for GLY. Li et al. (2013a) improved the representation of the gas-phase and aqueous-phase chemistry of dicarbonyls (GLY and MGLY) in the community multiscale air quality (CMAQ) modeling system to simulate SOA levels over the PRD region and made comparisons with observations. The simulated average SOA concentration was in better agreement with the observed mean SOA concentration after the improvement. Furthermore, dicarbonyls were found to make a large contribution ( $53 \%)$ to the simulated surface SOA formation, mainly via irreversible uptake by aqueous particles, whereas the contributions of dicarbonyls to SOA via gas-phase reactions can be negligible ( $\mathrm{Li}$ et al., 2013a). This finding was consistent with that of Hu et al. (2017), who used the CMAQ model to study the tempo-spatial distribution of SOA in China and found that the reactive surface uptake of GLY and MGLY was an important formation pathway for SOA, with respective contributions of $14 \%$ to $25 \%$ and $23 \%$ to $28 \%$.

Some laboratory experiments have also investigated the roles of monocarbonyls in SOA formation. The heterogeneous reactions of carbonyls can occur on various aerosol surfaces, including mineral particles, sea salt, and soot particles. Therefore, some laboratory studies have provided reliable uptake coefficients and identified the reaction products under various conditions (Shen et al., 2013; and references therein). Some studies have also attempted to quantify the contributions of some monocarbonyls to SOA formation. For example, assuming the partition efficiency of both oxalic and malonic acid to be $100 \%$, the aqueous $\mathrm{OH}$-oxidation of methacrolein and methyl vinyl ketone was reported to make maximum contributions of $8.8 \%$ and $23.8 \%$ to SOA formation, respectively, after a 7-h reaction (Zhang et al., 2010). However, the detailed formation mechanisms of SOA from carbonyls across China remain unclear and warrant further investigation.

\subsection{Human health}

The World Health Organization has classified several carbonyl species (e.g., $\mathrm{HCHO}$ and 
$\mathrm{CH}_{3} \mathrm{CHO}$ ) as toxic air pollutants and even human carcinogens. In the last two decades, the Chinese government has issued a series of standards to regulate indoor exposure to toxic carbonyl species, but few focused on outdoor carbonyls. Indoor carbonyls often exhibit high levels, and some even exceed the national standard (Huang et al., 2011; Lü et al., 2016; Lui et al., 2017b; Wang et al., 2007; Weng et al., 2009). Therefore, studies have been conducted to investigate the detrimental effects of both indoor and outdoor carbonyls on human health in China.

Based on numerous experimental studies and historical data, Cogliano et al. (2005) confirmed the carcinogenicity (e.g., nasopharyngeal cancer, leukemia, and sinonasal cancer) of $\mathrm{HCHO}$ in humans and animals. The acute and chronic toxicity effects of HCHO apart from carcinogenicity were also investigated (Cogliano et al., 2005; Tang et al., 2009; and references therein). Such laboratory studies of other carbonyl species are very scarce in China, and more investigations are urgently needed. In addition, few studies have focused on personal exposure levels and risk assessments. For example, Ho et al. (2015) conducted field studies in nine Chinese cities and assessed the potential health risks of $\mathrm{HCHO}$ and $\mathrm{CH}_{3} \mathrm{CHO}$ using a simple risk-calculation model. High cumulative cancer risks were found in summer in all cities except for Xiamen, a coastal city in southeast China. Furthermore, the highest risk was observed at Chengdu in summer and Wuhan in winter. High exposure and health risks of HCHO and $\mathrm{CH}_{3} \mathrm{CHO}$ were also found in public places in Hangzhou and Shanghai (Feng et al., 2010; Weng et al., 2009). In addition, Ho et al. (2014b), Huang et al. (2011), and Lü et al. (2016) investigated the health risks of indoor carbonyls at a university in Xiamen, two residential kitchens in Hong Kong, and a library in Guangzhou, respectively. Each identified $\mathrm{HCHO}$ exposure as a valid occupational health and safety concern. Furthermore, Tang et al. (2009) elucidated the indoor and outdoor exposure levels and health effects of $\mathrm{HCHO}$ across China in detail. Overall, these limited results revealed the high risk of exposure to carbonyls in China. More studies of the health impact of carbonyls are needed, and essential measures to protect human health should be taken.

\section{Summary and outlook}

Significant progress has been achieved in the last 20 years in the study of ambient carbonyls in China's atmosphere. A number of field observations have been conducted at various surface sites across China. The results have revealed the severity and tempo-spatial variations of carbonyls pollution in China. Photochemical formation was identified as the dominant source of ambient carbonyls, but primary emissions also made important contributions in specific circumstances. Alkenes, aromatics, and isoprene usually dominated the secondary formation of carbonyls. Carbonyls are acknowledged as important precursors of $\mathrm{O}_{3}$ and SOA. For $\mathrm{O}_{3}$, carbonyls usually dominate the OFP in rural areas, and for SOA, dicarbonyls such as GLY and MGLY make important contributions to SOA formation, mainly via irreversible uptake by aqueous particles. In addition, few studies have revealed the high exposure and health risk of both indoor and outdoor carbonyls in China.

Despite the abovementioned progress, more efforts are still needed to gain a thorough understanding of the role of carbonyls in tropospheric chemistry, $\mathrm{O}_{3}$ and SOA formation, and human health. The following directions are recommended for future study. 
(1) The current field observations remain far from sufficient to comprehensively reflect the carbonyls pollution situation across China. Although high-molecular weight carbonyls play a significant role in aerosol formation, the observational data available are very scarce because they are largely partitioned into the particle phase and thus exhibit low gas-phase concentrations. More studies should be conducted to investigate the characteristics of high-molecular weight carbonyls. Furthermore, the vertical distribution profiles for gaseous carbonyls remain unclear. In addition, most ground observations have been concentrated in fast-developing regions, such as the NCP, YRD, and PRD. It is strongly suggested that more field studies be conducted on other overpopulated and fast-developing regions. This suggestion also applies to other more reactive carbonyl species that should receive more attention.

(2) The emission patterns of primary sources (especially the non-vehicle primary sources) remain poorly understood. The combined efforts of the research community and government agencies are needed to accurately characterize the primary emissions and develop a national species-specific carbonyls emission inventory in China.

(3) Most studies have focused on identifying dominant precursors; little attention has been paid to the detailed photochemical formation processes of carbonyls. To some extent, such an investigation is impeded by the accurate representation of chemical mechanisms of carbonyls in models, which is still considered a difficulty in current research. We recommend that more laboratory experiments be conducted to update the chemical mechanisms that can be incorporated into models to better identify dominant precursors and investigate the detailed photochemical formation mechanisms of carbonyls. It can also help to precisely quantify the contributions of isoprene and other important biogenic VOCs to carbonyls.

(4) Due to the limitations of observation techniques, few studies have focused on the effects of carbonyls on $\mathrm{O}_{3}$ and SOA. Ways of better dissecting the contributions of primary and secondary carbonyls to $\mathrm{O}_{3}$ and better understanding the formation mechanisms of SOA from carbonyls remain significant challenges that require further investigation. In addition, research and control policy making should attach equal importance to indoor and outdoor exposure to carbonyls.

\section{Acknowledgements}

This work was funded by the National Natural Science Foundation of China (41675118, 91544213), the National Key Research and Development Program of China (2016YFC0200500), the Qilu Youth Talent Program of Shandong University, the Jiangsu Collaborative Innovation Center for Climate Change, and the Taishan Scholars (ts201712003).

\section{References}

Altemose, B., Gong, J., Zhu, T., Hu, M., Zhang, L., Cheng, H., Zhang, L., Tong, J., Kipen, H.M., Ohman-Strickland, P., 2015. Aldehydes in relation to air pollution sources: A case study around the Beijing Olympics. Atmos. Environ. 109, 61-69.

Atkinson, R., 2000. Atmospheric chemistry of VOCs and NOx. Atmos. Environ. 34, 2063-2101. 
Atkinson, R., Arey, J., 2003. Atmospheric degradation of volatile organic compounds. Chem. Rev. 103, 4605-4638.

Blake, R.S., Monks, P.S., Ellis, A.M., 2009. Proton-transfer reaction mass spectrometry. Chem. Rev. 109, 861-896.

Calvert, J., Mellouki, A., Orlando, J., Pilling, M., Wallington, T., 2011. The Mechanisms of Atmospheric Oxidation of the Oxygenates. Oxford University Press: New York.

Cerón, R., Cerón, J., Muriel, M., 2007. Diurnal and seasonal trends in carbonyl levels in a semiurban coastal site in the Gulf of Campeche, Mexico. Atmos. Environ. 41, 63-71.

Chan Miller, C., Jacob, D.J., González Abad, G., Chance, K., 2016. Hotspot of glyoxal over the Pearl River delta seen from the OMI satellite instrument: implications for emissions of aromatic hydrocarbons. Atmos. Chem. Phys. 16, 4631-4639.

Chen, W., Shao, M., Lu, S., Wang, M., Zeng, L., Yuan, B., Liu, Y., 2014. Understanding primary and secondary sources of ambient carbonyl compounds in Beijing using the PMF model. Atmos. Chem. Phys. 14, 3047-3062.

Cheng, Y., Lee, S., Huang, Y., Ho, K., Ho, S., Yau, P., Louie, P., Zhang, R., 2014. Diurnal and seasonal trends of carbonyl compounds in roadside, urban, and suburban environment of Hong Kong. Atmos. Environ. 89, 43-51.

Chi, Y., Feng, Y., Wen, S., Lü, H., Yu, Z., Zhang, W., Sheng, G., Fu, J., 2007. Determination of carbonyl compounds in the atmosphere by DNPH derivatization and LC-ESI-MS/MS detection. Talanta 72, 539-545.

Chi, Y., Li, Z., Feng, Y., Wen, S., Yu, Z., Sheng, G., Fu, J., 2008. Carbonyl compound concentrations in the air at Dinghu Mountain, Guangdong Province. Acta Scien. Circum. 28.

Cogliano, V.J., Grosse, Y., Baan, R.A., Straif, K., Secretan, M.B., Ghissassi, F.E., 2005. Meeting report: summary of IARC monographs on formaldehyde, 2-butoxyethanol, and 1-tert-butoxy-2-propanol. Environ. Health Perspect. 113, 1205-1208.

Cui, L., Zhang, Z., Huang, Y., Lee, S.C., Blake, D.R., Ho, K.F., Wang, B., Gao, Y., Wang, X.M., Louie, P.K.K., 2016. Measuring OVOCs and VOCs by PTR-MS in an urban roadside microenvironment of Hong Kong: relative humidity and temperature dependence, and field intercomparisons. Atmos. Meas. Tech. 9, 5763-5779.

Dai, W., Ho, S.S.H., Ho, K., Liu, W., Cao, J., Lee, S., 2012. Seasonal and diurnal variations of mono-and di-carbonyls in Xi'an, China. Atmos. Res. 113, 102-112.

Duan, J., Guo, S., Tan, J., Wang, S., Chai, F., 2012. Characteristics of atmospheric carbonyls during haze days in Beijing, China. Atmos. Res. 114, 17-27.

Duan, J., Tan, J., Yang, L., Wu, S., Hao, J., 2008. Concentration, sources and ozone formation potential of volatile organic compounds (VOCs) during ozone episode in Beijing. Atmos. Res. 88, 25-35.

Feng, Y., Mu, C., Zhai, J., Li, J., Zou, T., 2010. Characteristics and personal exposures of carbonyl compounds in the subway stations and in-subway trains of Shanghai, China. J. Hazard. Mater. 183, 574-582.

Feng, Y., Wen, S., Chen, Y., Wang, X., Lü, H., Bi, X., Sheng, G., Fu, J., 2005. Ambient levels of carbonyl compounds and their sources in Guangzhou, China. Atmos. Environ. 39, 1789-1800. 
Fu, T.M., Jacob, D.J., Wittrock, F., Burrows, J.P., Vrekoussis, M., Henze, D.K., 2008. Global budgets of atmospheric glyoxal and methylglyoxal, and implications for formation of secondary organic aerosols. J. Geophys. Res. 113.

Fuchs, H., Tan, Z., Lu, K., Bohn, B., Broch, S., Brown, S.S., Dong, H., Gomm, S., Häseler, R., He, L., 2017. OH reactivity at a rural site (Wangdu) in the North China Plain: contributions from $\mathrm{OH}$ reactants and experimental $\mathrm{OH}$ budget. Atmos. Chem. Phys. 17, 645-661.

Guenther, A., Jiang, X., Heald, C., Sakulyanontvittaya, T., Duhl, T., Emmons, L., Wang, X., 2012. The Model of Emissions of Gases and Aerosols from Nature version 2.1 (MEGAN2. 1): an extended and updated framework for modeling biogenic emissions. Geosci. Model Dev. 5, 1471-1492.

Guo, H., Jiang, F., Cheng, H., Simpson, I., Wang, X., Ding, A., Wang, T., Saunders, S., Wang, T., Lam, S., 2009. Concurrent observations of air pollutants at two sites in the Pearl River Delta and the implication of regional transport. Atmos. Chem. Phys. 9, 7343-7360.

Guo, H., Lee, S., Louie, P., Ho, K., 2004a. Characterization of hydrocarbons, halocarbons and carbonyls in the atmosphere of Hong Kong. Chemosphere 57, 1363-1372.

Guo, H., Ling, Z., Cheung, K., Wang, D., Simpson, I., Blake, D., 2013. Acetone in the atmosphere of Hong Kong: Abundance, sources and photochemical precursors. Atmos. Environ. 65, 80-88.

Guo, H., Wang, T., Blake, D., Simpson, I., Kwok, Y., Li, Y., 2006. Regional and local contributions to ambient non-methane volatile organic compounds at a polluted rural/coastal site in Pearl River Delta, China. Atmos. Environ. 40, 2345-2359.

Guo, H., Wang, T., Simpson, I., Blake, D., Yu, X., Kwok, Y., Li, Y., 2004b. Source contributions to ambient VOCs and $\mathrm{CO}$ at a rural site in eastern China. Atmos. Environ. 38, 4551-4560.

Guo, S., Chen, M., 2013. ${ }^{13} \mathrm{C}$ isotope evidence for photochemical production of atmospheric formaldehyde, acetaldehyde, and acetone pollutants in Guangzhou. Environ. Chem. Lett. $11,77-82$.

Guo, S., Chen, M., He, X., Yang, W., Tan, J., 2014a. Seasonal and diurnal characteristics of carbonyls in urban air in Qinzhou, China. Aerosol Air Qual. Res. 14, 1653-1664.

Guo, S., Chen, M., Tan, J., 2016. Seasonal and diurnal characteristics of atmospheric carbonyls in Nanning, China. Atmos. Res. 169, 46-53.

Guo, S., He, X., Chen, M., Tan, J., Wang, Y., 2014b. Photochemical production of atmospheric carbonyls in a rural area in southern China. Arch. Environ. Contam. Toxicol. 66, 594-605.

He, X., Tan, J., Guo, S., Ma, Y., He, K., 2016. Chemical Characteristics and Sources of Atmospheric Carbonyls during the 2014 Beijing APEC. Environ. Sci. 37.

Ho, K., Ho, S.S.H., Cheng, Y., Lee, S., Yu, J.Z., 2007. Real-world emission factors of fifteen carbonyl compounds measured in a Hong Kong tunnel. Atmos. Environ. 41, 1747-1758.

Ho, K., Ho, S.S.H., Dai, W., Cao, J.J., Huang, R.J., Tian, L., Deng, W., 2014a. Seasonal variations of monocarbonyl and dicarbonyl in urban and sub-urban sites of Xi'an, China. Environ. Monit. Assess. 186, 2835-2849.

Ho, K., Ho, S.S.H., Huang, R.J., Dai, W., Cao, J.J., Tian, L., Deng, W., 2015. Spatiotemporal distribution of carbonyl compounds in China. Environ. Pollut. 197, 316-324.

Ho, K., Lee, S., Louie, P.K., Zou, S., 2002. Seasonal variation of carbonyl compound concentrations in urban area of Hong Kong. Atmos. Environ. 36, 1259-1265. 
Ho, S.S.H., Ho, K.F., Lee, S.C., Cheng, Y., Yu, J.Z., Lam, K.M., Feng, N.S.Y., Huang, Y., 2012. Carbonyl emissions from vehicular exhausts sources in Hong Kong. J. Air Waste Manage. Assoc. 62, 221-234.

Ho, S.S.H., Ip, H.S.S., Ho, K.F., Ng, L.P.T., Dai, W., Cao, J., Chan, C.S., Ho, L.B., $2014 b$. Evaluation of hazardous airborne carbonyls on a university campus in southern China. J. Air Waste Manage. Assoc. 64, 903-916.

Ho, S.S.H., Yu, J.Z., 2002. Feasibility of collection and analysis of airborne carbonyls by onsorbent derivatization and thermal desorption. Anal. Chem. 74, 1232-1240.

Ho, S.S.H., Yu, J.Z., 2004. Determination of airborne carbonyls: Comparison of a thermal desorption/GC method with the standard DNPH/HPLC method. Environ. Sci. Technol. 38, 862-870.

Hu, J., Wang, P., Ying, Q., Zhang, H., Chen, J., Ge, X., Li, X., Jiang, J., Wang, S., Zhang, J., 2017. Modeling biogenic and anthropogenic secondary organic aerosol in China. Atmos. Chem. Phys. 17, 77-92.

Huang, J., Feng, Y., Li, J., Xiong, B., Feng, J., Wen, S., Sheng, G., Fu, J., Wu, M., 2008. Characteristics of carbonyl compounds in ambient air of Shanghai, China. J. Atmos. Chem. 61, 1-20.

Huang, J., Feng, Y., Xiong, B., Fu, J., Sheng, G., 2009. Ambient Levels of Carbonyl Compounds in Shanghai, China. Environ. Sci. 30.

Huang, Y., Ho, S.S.H., Ho, K.F., Lee, S.C., Yu, J.Z., Louie, P.K., 2011. Characteristics and health impacts of VOCs and carbonyls associated with residential cooking activities in Hong Kong. J. Hazard. Mater. 186, 344-351.

Inomata, S., Tanimoto, H., Kameyama, S., Tsunogai, U., Irie, H., Kanaya, Y., Wang, Z., 2008. Determination of formaldehyde mixing ratios in air with PTR-MS: laboratory experiments and field measurements. Atmos. Chem. Phys. 8, 273-284.

Jacob, D.J., Field, B.D., Jin, E.M., Bey, I., Li, Q., Logan, J.A., Yantosca, R.M., Singh, H.B., 2002. Atmospheric budget of acetone. J. Geophys. Res. 107, ACH 5-1-ACH 5-17.

Jia, C., Wang, Y., Li, Y., Huang, T., Mao, X., Mo, J., Li, J., Wanyanhan, J., Liang, X., Gao, H., 2018. Oxidative Capacity and Radical Chemistry in a Semi-arid and Petrochemicalindustrialized City, Northwest China. Aerosol Air Qual. Res. 18, 1391-1404.

Jiang, D., 2015. Current Pollution Status of Aldoketones Compounds in the Ambient Air of Shenyang. Environ. Prot. Sci. 41.

Jiang, Z., Wang, Y., Zheng, X., Liu, X., Xia, C., Xiao, X., Li, S., 2016. Variation Characteristics of Atmospheric Carbonyl Compounds in Zhangjiajie Forest. Res. Environ. Sci. 29, 12721278.

Kanaya, Y., Pochanart, P., Liu, Y., Li, J., Tanimoto, H., Kato, S., Suthawaree, J., Inomata, S., Taketani, F., Okuzawa, K., 2009. Rates and regimes of photochemical ozone production over Central East China in June 2006: a box model analysis using comprehensive measurements of ozone precursors. Atmos. Chem. Phys. 9, 7711-7723.

Kawamura, K., Okuzawa, K., Aggarwal, S., Irie, H., Kanaya, Y., Wang, Z., 2013. Determination of gaseous and particulate carbonyls (glycolaldehyde, hydroxyacetone, glyoxal, methylglyoxal, nonanal and decanal) in the atmosphere at Mt. Tai. Atmos. Chem. Phys. 13, 5369-5380. 
Li, L., Xie, S., 2014. Historical variations of biogenic volatile organic compound emission inventories in China, 1981-2003. Atmos. Environ. 95, 185-196.

Li, N., Fu, T.M., Cao, J., Lee, S., Huang, X., He, L., Ho, K.F., Fu, J.S., Lam, Y.F., 2013a. Sources of secondary organic aerosols in the Pearl River Delta region in fall: Contributions from the aqueous reactive uptake of dicarbonyls. Atmos. Environ. 76, 200207.

Li, X., Brauers, T., Hofzumahaus, A., Lu, K., Li, Y., Shao, M., Wagner, T., Wahner, A., 2013b. MAX-DOAS measurements of $\mathrm{NO}_{2}, \mathrm{HCHO}$ and $\mathrm{CHOCHO}$ at a rural site in Southern China. Atmos. Chem. Phys. 13, 2133-2151.

Li, X., Rohrer, F., Brauers, T., Hofzumahaus, A., Lu, K., Shao, M., Zhang, Y., Wahner, A., 2014. Modeling of $\mathrm{HCHO}$ and $\mathrm{CHOCHO}$ at a semi-rural site in southern China during the PRIDE-PRD2006 campaign. Atmos. Chem. Phys. 14, 12291-12305.

Li, Y., Shao, M., Lu, S., Chang, C.C., Dasgupta, P.K., 2010. Variations and sources of ambient formaldehyde for the 2008 Beijing Olympic games. Atmos. Environ. 44, 2632-2639.

Li, Z., Xue, L., Yang, X., Zha, Q., Tham, Y.J., Yan, C., Louie, P.K., Luk, C.W., Wang, T., Wang, W., 2018. Oxidizing capacity of the rural atmosphere in Hong Kong, Southern China. Sci. Total Environ. 612, 1114-1122.

Ling, Z., Guo, H., Chen, G., Lam, S.H.M., Fan, S., 2016. Formaldehyde and acetaldehyde at different elevations in mountainous areas in Hong Kong. Aerosol Air Qual. Res. 16, 18681878.

Ling, Z., Zhao, J., Fan, S., Wang, X., 2017. Sources of formaldehyde and their contributions to photochemical $\mathrm{O}_{3}$ formation at an urban site in the Pearl River Delta, southern China. Chemosphere 168, 1293-1301.

Liu, Y., Shao, M., Kuster, W.C., Goldan, P.D., Li, X., Lu, S., Gouw, J.A.d., 2009. Source identification of reactive hydrocarbons and oxygenated VOCs in the summertime in Beijing. Environ. Sci. Technol. 43, 75-81.

Liu, Y., Yuan, B., Li, X., Shao, M., Lu, S., Li, Y., Chang, C., Wang, Z., Hu, W., Huang, X., 2015. Impact of pollution controls in Beijing on atmospheric oxygenated volatile organic compounds (OVOCs) during the 2008 Olympic Games: observation and modeling implications. Atmos. Chem. Phys. 15, 3045-3062.

Liu, Z., Wang, Y., Gu, D., Zhao, C., Huey, L., Stickel, R., Liao, J., Shao, M., Zhu, T., Zeng, L., 2012a. Summertime photochemistry during CAREBeijing-2007: ROx budgets and $\mathrm{O}_{3}$ formation. Atmos. Chem. Phys. 12, 7737-7752.

Liu, Z., Wang, Y., Vrekoussis, M., Richter, A., Wittrock, F., Burrows, J.P., Shao, M., Chang, C.C., Liu, S.C., Wang, H., 2012b. Exploring the missing source of glyoxal (CHOCHO) over China. Geophys. Res. Lett. 39.

Lou, S., Holland, F., Rohrer, F., Lu, K., Bohn, B., Brauers, T., Chang, C., Fuchs, H., Häseler, R., Kita, K., 2010. Atmospheric OH reactivities in the Pearl River Delta-China in summer 2006: measurement and model results. Atmos. Chem. Phys. 10, 11243-11260.

Lü, H., Cai, Q.Y., Wen, S., Chi, Y., Guo, S., Sheng, G., Fu, J., 2010. Seasonal and diurnal variations of carbonyl compounds in the urban atmosphere of Guangzhou, China. Sci. Total Environ. 408, 3523-3529. 
Lü, H., Cai, Q.Y., Wen, S., Chi, Y., Guo, S., Sheng, G., Fu, J., Antizar-Ladislao, B., 2009. Carbonyl compounds in the ambient air of hazy days and clear days in Guangzhou, China. Atmos. Res. 94, 363-372.

Lü, H., Tian, J.J., Cai, Q.Y., Wen, S., Liu, Y., Li, N., 2016. Levels and health risk of carbonyl compounds in air of the library in Guangzhou, South China. Aerosol Air Qual. Res. 16, 1234-1243.

Lui, K.H., Dai, W.T., Chan, C., Ho, S.S.H., Cao, J.J., Lee, S., Ho, K., 2017a. Spatial distributions of airborne di-carbonyls in urban and rural areas in China. Atmos. Res. 186, $1-8$.

Lui, K.H., Dai, W.T., Chan, C.S., Tian, L., Ning, B.F., Zhou, Y., Song, X., Wang, B., Li, J., Cao, J.J., 2017b. Cancer risk from gaseous carbonyl compounds in indoor environment generated from household coal combustion in Xuanwei, China. Environ. Sci. Pollut. Res. 24, 17500-17510.

Lui, K.H., Ho, S.S.H., Louie, P.K., Chan, C., Lee, S., Hu, D., Chan, P., Lee, J.C.W., Ho, K., 2017c. Seasonal behavior of carbonyls and source characterization of formaldehyde (HCHO) in ambient air. Atmos. Environ. 152, 51-60.

Ma, Y., Diao, Y., Zhang, B., Wang, W., Ren, X., Yang, D., Wang, M., Shi, X., Zheng, J., 2016. Detection of formaldehyde emissions from an industrial zone in the Yangtze River Delta region of China using a proton transfer reaction ion-drift chemical ionization mass spectrometer. Atmos. Meas. Tech. 9, 6101.

Mason, S.A., Field, R.J., Yokelson, R.J., Kochivar, M.A., Tinsley, M.R., Ward, D.E., Hao, W.M., 2001. Complex effects arising in smoke plume simulations due to inclusion of direct emissions of oxygenated organic species from biomass combustion. J. Geophys. Res. 106, 12527-12539.

Mellouki, A., Wallington, T., Chen, J., 2015. Atmospheric chemistry of oxygenated volatile organic compounds: impacts on air quality and climate. Chem. Rev. 115, 3984-4014.

Mo, Z., Shao, M., Lu, S., 2016. Compilation of a source profile database for hydrocarbon and OVOC emissions in China. Atmos. Environ. 143, 209-217.

Mu, Y., Pang, X., Quan, J., Zhang, X., 2007. Atmospheric carbonyl compounds in Chinese background area: A remote mountain of the Qinghai-Tibetan Plateau. J. Geophys. Res. 112.

Nan, J., Wang, S., Guo, Y., Xiang, Y., Zhou, B., 2017. Study on the daytime OH radical and implication for its relationship with fine particles over megacity of Shanghai, China. Atmos. Environ. 154, 167-178.

Pang, X., Lee, X., 2010. Temporal variations of atmospheric carbonyls in urban ambient air and street canyons of a Mountainous city in Southwest China. Atmos. Environ. 44, 20982106.

Pang, X., Lewis, A.C., Hamilton, J.F., 2011. Determination of airborne carbonyls via pentafluorophenylhydrazine derivatisation by GC-MS and its comparison with HPLC method. Talanta 85, 406-414.

Pang, X., Mu, Y., 2006. Seasonal and diurnal variations of carbonyl compounds in Beijing ambient air. Atmos. Environ. 40, 6313-6320.

Pang, X., Mu, Y., Lee, X., Zhang, Y., Xu, Z., 2009a. Influences of characteristic meteorological conditions on atmospheric carbonyls in Beijing, China. Atmos. Res. 93, 913-919. 
Pang, X., Mu, Y., Zhang, Y., Lee, X., Yuan, J., 2009b. Contribution of isoprene to formaldehyde and ozone formation based on its oxidation products measurement in Beijing, China. Atmos. Environ. 43, 2142-2147.

Rao, Z., Chen, Z., Liang, H., Huang, L., Huang, D., 2016. Carbonyl compounds over urban Beijing: Concentrations on haze and non-haze days and effects on radical chemistry. Atmos. Environ. 124, 207-216.

Seco, R., Penuelas, J., Filella, I., 2007. Short-chain oxygenated VOCs: Emission and uptake by plants and atmospheric sources, sinks, and concentrations. Atmos. Environ. 41, 24772499.

Shao, M., Lu, S., Liu, Y., Xie, X., Chang, C., Huang, S., Chen, Z., 2009. Volatile organic compounds measured in summer in Beijing and their role in ground-level ozone formation. J. Geophys. Res. 114.

Shen, X., Zhao, Y., Chen, Z., Huang, D., 2013. Heterogeneous reactions of volatile organic compounds in the atmosphere. Atmos. Environ. 68, 297-314.

Sheng, J., Zhao, D., Ding, D., Li, X., Huang, M., Gao, Y., Quan, J., Zhang, Q., 2018. Characterizing the level, photochemical reactivity, emission, and source contribution of the volatile organic compounds based on PTR-TOF-MS during winter haze period in Beijing, China. Atmos. Res. 212, 54-63.

Shi, J., Pang, X., Bai, Z., Jin, L., Li, W., Kong, S., 2011. Measurement of Carbonyl Compounds in Ambient Air of Tianjin City and Bohai Sea. J. Tianjin Univ. 44.

Szulejko, J.E., Kim, K.-H., 2015. Derivatization techniques for determination of carbonyls in air. Trac-Trends Anal. Chem. 64, 29-41.

Tan, P., Yu, Y., Jiang, H., Liu, Z., 2002. Analysis and concentration variability of carbonyl compounds in Qingdao atmosphere. China Environ. Sci. 22, 451-455.

Tan, Z., Lu, K., Jiang, M., Su, R., Dong, H., Zeng, L., Xie, S., Tan, Q., Zhang, Y., 2018. Exploring ozone pollution in Chengdu, southwestern China: A case study from radical chemistry to O3-VOC-NOx sensitivity. Sci. Total Environ. 636, 775-786.

Tang, X., Bai, Y., Duong, A., Smith, M.T., Li, L., Zhang, L., 2009. Formaldehyde in China: production, consumption, exposure levels, and health effects. Environ. Int. 35, 1210-1224.

Wang, B., Lee, S., Ho, K., 2007. Characteristics of carbonyls: concentrations and source strengths for indoor and outdoor residential microenvironments in China. Atmos. Environ. 41, 2851-2861.

Wang, B., Liu, C., Lv, W., Shao, M., Zhang, Y., 2009a. Character of Volatile Carbonyl Compounds and Their Source in Guangzhou Ambient Air. Environ. Sci. 30.

Wang, B., Liu, Y., Shao, M., Lu, S., Wang, M., Yuan, B., Gong, Z., He, L., Zeng, L., Hu, M., 2016. The contributions of biomass burning to primary and secondary organics: A case study in Pearl River Delta (PRD), China. Sci. Total Environ. 569, 548-556.

Wang, C., Huang, X.F., Han, Y., Zhu, B., He, L.Y., 2017a. Sources and potential photochemical roles of formaldehyde in an urban atmosphere in South China. J. Geophys. Res. 122.

Wang, H., Huang, C., Chen, K., Peng, Y., Lai, C., 2010a. Measurement and source characteristics of carbonyl compounds in the atmosphere in Kaohsiung city, Taiwan. J. Hazard. Mater. 179, 1115-1121. 
Wang, L., Wang, W., Zhao, X., Xu, X., 2014a. Pollution Characteristics and Sources of Carbonyl Compounds in Zhengzhou Ambient Air of Winter and Summer. China Environ. Monit. 30.

Wang, M., Chen, W., Shao, M., Lu, S., Zeng, L., Hu, M., 2015. Investigation of carbonyl compound sources at a rural site in the Yangtze River Delta region of China. J. Environ. Sci. 28, 128-136.

Wang, M., Zeng, L., Lu, S., Shao, M., Liu, X., Yu, X., Chen, W., Yuan, B., Zhang, Q., Hu, M., 2014b. Development and validation of a cryogen-free automatic gas chromatograph system (GC-MS/FID) for online measurements of volatile organic compounds. Anal. Methods 6, 9424-9434.

Wang, T., Wei, X., Ding, A., Poon, S.C., Lam, K., Li, Y., Chan, L., Anson, M., 2009 b. Increasing surface ozone concentrations in the background atmosphere of Southern China, 1994-2007. Atmos. Chem. Phys. 9.

Wang, T., Xue, L., Brimblecombe, P., Lam, Y.F., Li, L., Zhang, L., 2017b. Ozone pollution in China: A review of concentrations, meteorological influences, chemical precursors, and effects. Sci. Total Environ. 575, 1582-1596.

Wang, X., Wang, H., Wang, S., 2010b. Ambient formaldehyde and its contributing factor to ozone and $\mathrm{OH}$ radical in a rural area. Atmos. Environ. 44, 2074-2078.

Wang, Y., Guo, H., Zou, S., Lyu, X., Ling, Z., Cheng, H., Zeren, Y., 2018. Surface O3 photochemistry over the South China Sea: Application of a near-explicit chemical mechanism box model. Environ. Pollut. 234, 155-166.

Warneke, C., De Gouw, J.A., Holloway, J.S., Peischl, J., Ryerson, T.B., Atlas, E., Blake, D., Trainer, M., Parrish, D.D., 2012. Multiyear trends in volatile organic compounds in Los Angeles, California: Five decades of decreasing emissions. J. Geophys. Res. 117.

Weng, M., Zhu, L., Yang, K., Chen, S., 2009. Levels and health risks of carbonyl compounds in selected public places in Hangzhou, China. J. Hazard. Mater. 164, 700-706.

Xu, Z., Huang, X., Nie, W., Chi, X., Xu, Z., Zheng, L., Sun, P., Ding, A., 2017. Influence of synoptic condition and holiday effects on VOCs and ozone production in the Yangtze River Delta region, China. Atmos. Environ. 168, 112-124.

Xu, Z., Liu, J., Zhang, Y., Liang, P., Mu, Y., 2010. Ambient levels of atmospheric carbonyls in Beijing during the 2008 Olympic Games. J. Environ. Sci. 22, 1348-1356.

Xue, L., Gu, R., Wang, T., Wang, X., Saunders, S., Blake, D., Louie, P.K., Luk, C.W., Simpson, I., Xu, Z., 2016. Oxidative capacity and radical chemistry in the polluted atmosphere of Hong Kong and Pearl River Delta region: analysis of a severe photochemical smog episode. Atmos. Chem. Phys. 16.

Xue, L., Wang, T., Gao, J., Ding, A., Zhou, X., Blake, D., Wang, X., Saunders, S., Fan, S., Zuo, H., 2014. Ground-level ozone in four Chinese cities: precursors, regional transport and heterogeneous processes. Atmos. Chem. Phys. 14, 13175-13188.

Xue, L., Wang, T., Guo, H., Blake, D., Tang, J., Zhang, X., Saunders, S., Wang, W., 2013. Sources and photochemistry of volatile organic compounds in the remote atmosphere of western China: results from the Mt. Waliguan Observatory. Atmos. Chem. Phys. 13, 85518567.

Yang, X., Xue, L., Wang, T., Wang, X., Gao, J., Lee, S., Blake, D.R., Chai, F., Wang, W., 2018. Observations and explicit modeling of summertime carbonyl formation in Beijing: 
Identification of key precursor species and their impact on atmospheric oxidation chemistry. J. Geophys. Res. 123, 1426-1440.

Yang, X., Xue, L., Yao, L., Li, Q., Wen, L., Zhu, Y., Chen, T., Wang, X., Yang, L., Wang, T., 2017. Carbonyl compounds at Mount Tai in the North China Plain: Characteristics, sources, and effects on ozone formation. Atmos. Res. 196, 53-61.

Yu, Y., Wen, S., Lü, H., Feng, Y., Wang, X., Sheng, G., Fu, J., 2008. Characteristics of atmospheric carbonyls and VOCs in Forest Park in South China. Environ. Monit. Assess. $137,275-285$.

Yuan, B., Chen, W., Shao, M., Wang, M., Lu, S., Wang, B., Liu, Y., Chang, C.C., Wang, B., 2012a. Measurements of ambient hydrocarbons and carbonyls in the Pearl River Delta (PRD), China. Atmos. Res. 116, 93-104.

Yuan, B., Hu, W., Shao, M., Wang, M., Chen, W., Lu, S., Zeng, L., Hu, M., 2013. VOC emissions, evolutions and contributions to SOA formation at a receptor site in eastern China. Atmos. Chem. Phys. 13, 8815-8832.

Yuan, B., Koss, A.R., Warneke, C., Coggon, M., Sekimoto, K., de Gouw, J.A., 2017. Protontransfer-reaction mass spectrometry: Applications in atmospheric sciences. Chem. Rev. $117,13187-13229$.

Yuan, B., Koss, A.R., Warneke, C., Gilman, J.B., Lerner, B.M., Stark, H., de Gouw, J.A., 2016. A high-resolution time-of-flight chemical ionization mass spectrometer utilizing hydronium ions $\left(\mathrm{H}_{3} \mathrm{O}^{+}\right.$ToF-CIMS) for measurements of volatile organic compounds in the atmosphere. Atmos. Meas. Tech. 9.

Yuan, B., Liu, Y., Shao, M., Lu, S., Streets, D.G., 2010. Biomass burning contributions to ambient VOCs species at a receptor site in the Pearl River Delta (PRD), China. Environ. Sci. Technol. 44, 4577-4582.

Yuan, B., Shao, M., de Gouw, J., Parrish, D.D., Lu, S., Wang, M., Zeng, L., Zhang, Q., Song, Y., Zhang, J., 2012b. Volatile organic compounds (VOCs) in urban air: How chemistry affects the interpretation of positive matrix factorization (PMF) analysis. J. Geophys. Res. 117.

Zhang, X., Chen, Z., Zhao, Y., 2010. Laboratory simulation for the aqueous OH-oxidation of methyl vinyl ketone and methacrolein: significance to the in-cloud SOA production. Atmos. Chem. Phys. 10, 9551-9561.

Zhang, Y., Mu, Y., Meng, F., Li, H., Wang, X., Zhang, W., Mellouki, A., Gao, J., Zhang, X., Wang, S., 2014. The pollution levels of BTEX and carbonyls under haze and non-haze days in Beijing, China. Sci. Total Environ. 490, 391-396.

Zhang, Y., Wang, X., Wen, S., Herrmann, H., Yang, W., Huang, X., Zhang, Z., Huang, Z., He, Q., George, C., 2016. On-road vehicle emissions of glyoxal and methylglyoxal from tunnel tests in urban Guangzhou, China. Atmos. Environ. 127, 55-60.

Zhou, X., Tan, J., Xiang, P., He, X., Guo, S., Duan, J., He, K., Ma, Y., Deng, S., Situ, S., 2017. Chemical characteristics of atmospheric carbonyls in winter and summer in Foshan City. China Environ. Sci. 37, 844-850. 


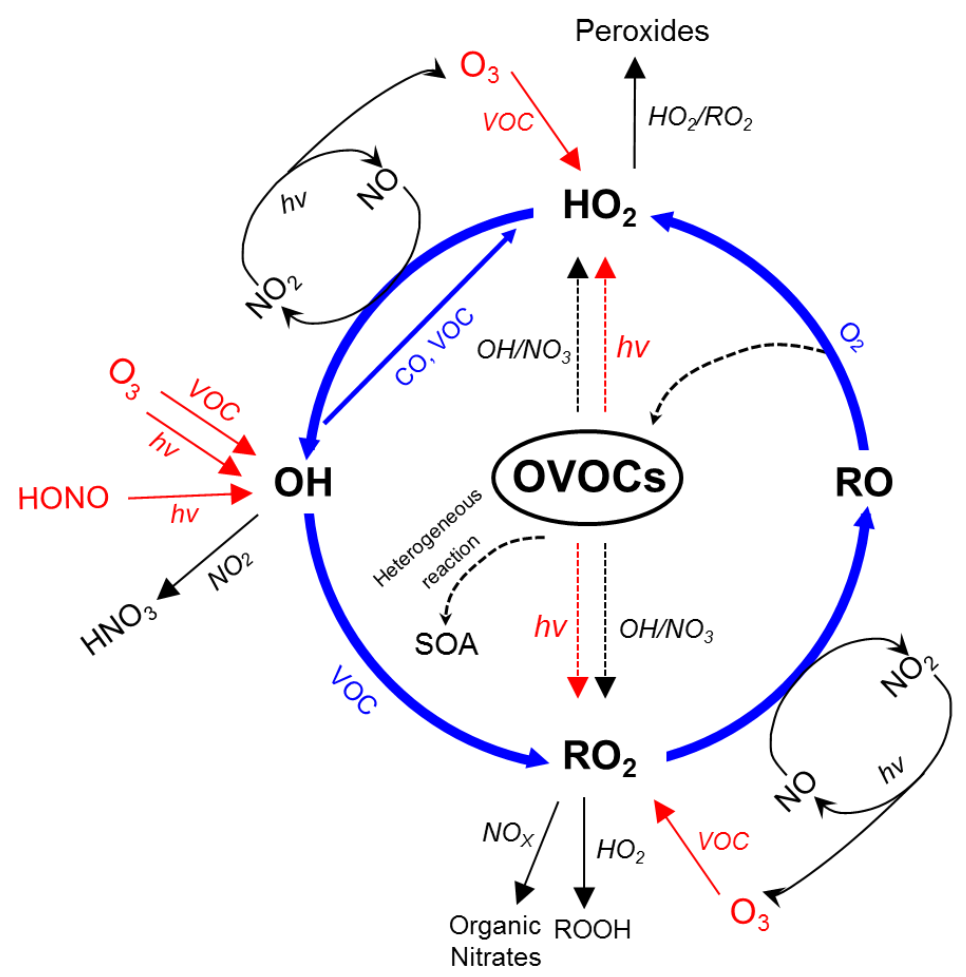

Figure 1. Major chemical processes of OVOCs in the atmosphere. The red and blue lines indicate the initiation and recycling pathways of radicals. The dotted lines indicate chemical processes in which OVOCs directly involved.
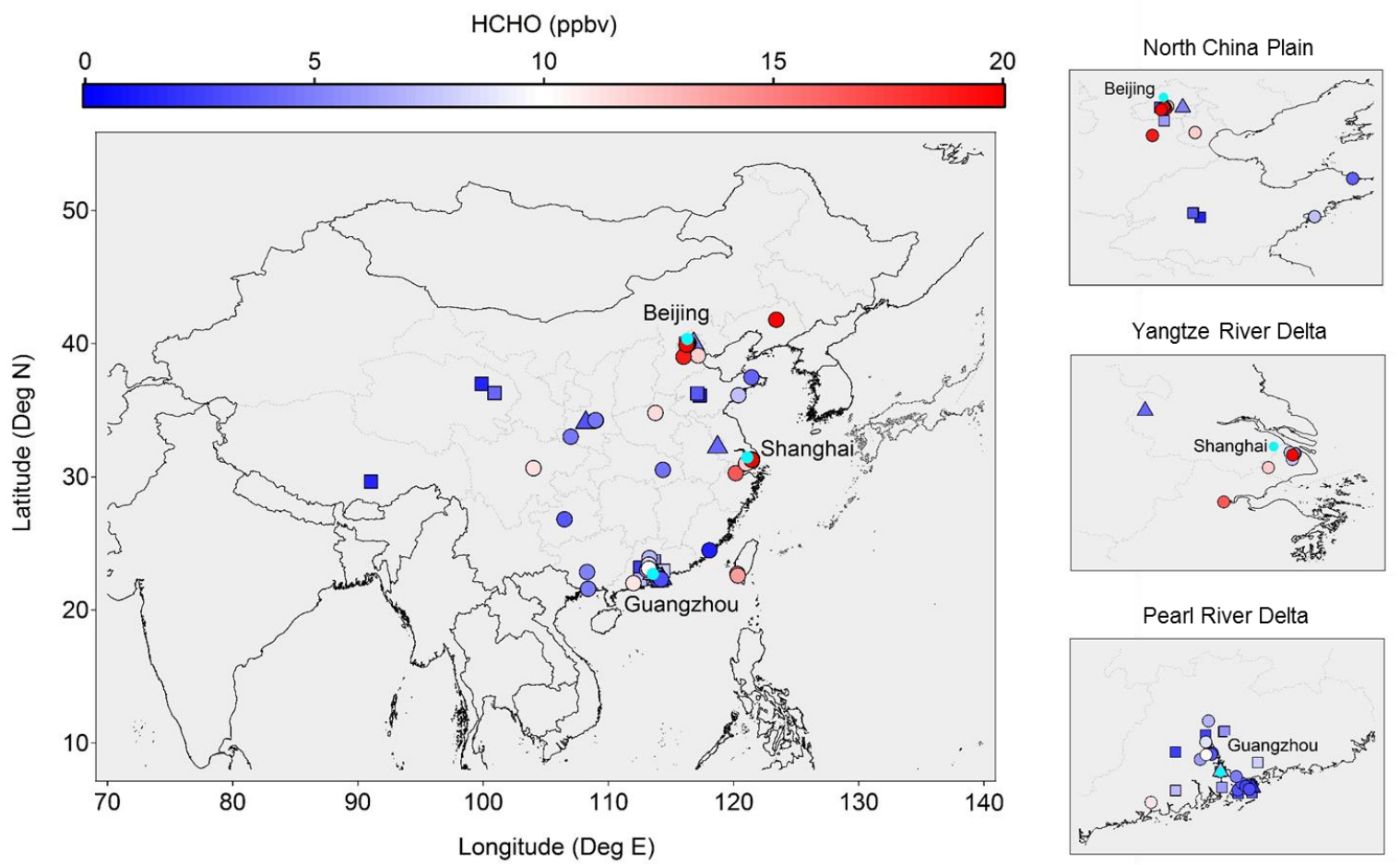

Figure 2a. Spatial distributions of HCHO levels (ppbv) in China. Urban, suburban, rural sites are marked as circles, triangles and squares, respectively. The observation data are taken from 
1013 Altemose et al. (2015), Cheng et al. (2014), Chi et al. (2008), Dai et al. (2012), Duan et al. 1014 (2012), Duan et al. (2008), Guo et al. (2009), Guo et al. (2013), Guo et al. (2014a), Guo et al. 1015 (2016), He et al. (2016), Ho et al. (2014a), Ho et al. (2015), Ho et al. (2002), Huang et al. 1016 (2008), Huang et al. (2009), Jiang (2015), Kanaya et al. (2009), Li et al. (2010), Li et al. (2018), 1017 Ling et al. (2016), Ling et al. (2017), Liu et al. (2015), Liu et al. (2012a), Lü et al. (2010), Lü 1018 et al. (2009), Lui et al. (2017a), Lui et al. (2017c), Ma et al. (2016), Mu et al. (2007), Nan et al. 1019 (2017), Pang and Lee (2010), Pang and Mu (2006), Rao et al. (2016), Shao et al. (2009), Shi et 1020 al. (2011), Tan et al. (2002), Wang et al. (2007), Wang et al. (2009a), Wang et al. (2017a), Wang 1021 et al. (2010a), Wang et al. (2014a), Wang et al. (2010b), Weng et al. (2009), Xu et al. (2010), 1022 Yang et al. (2018), Yang et al. (2017), Yu et al. (2008), and Yuan et al. (2012a).
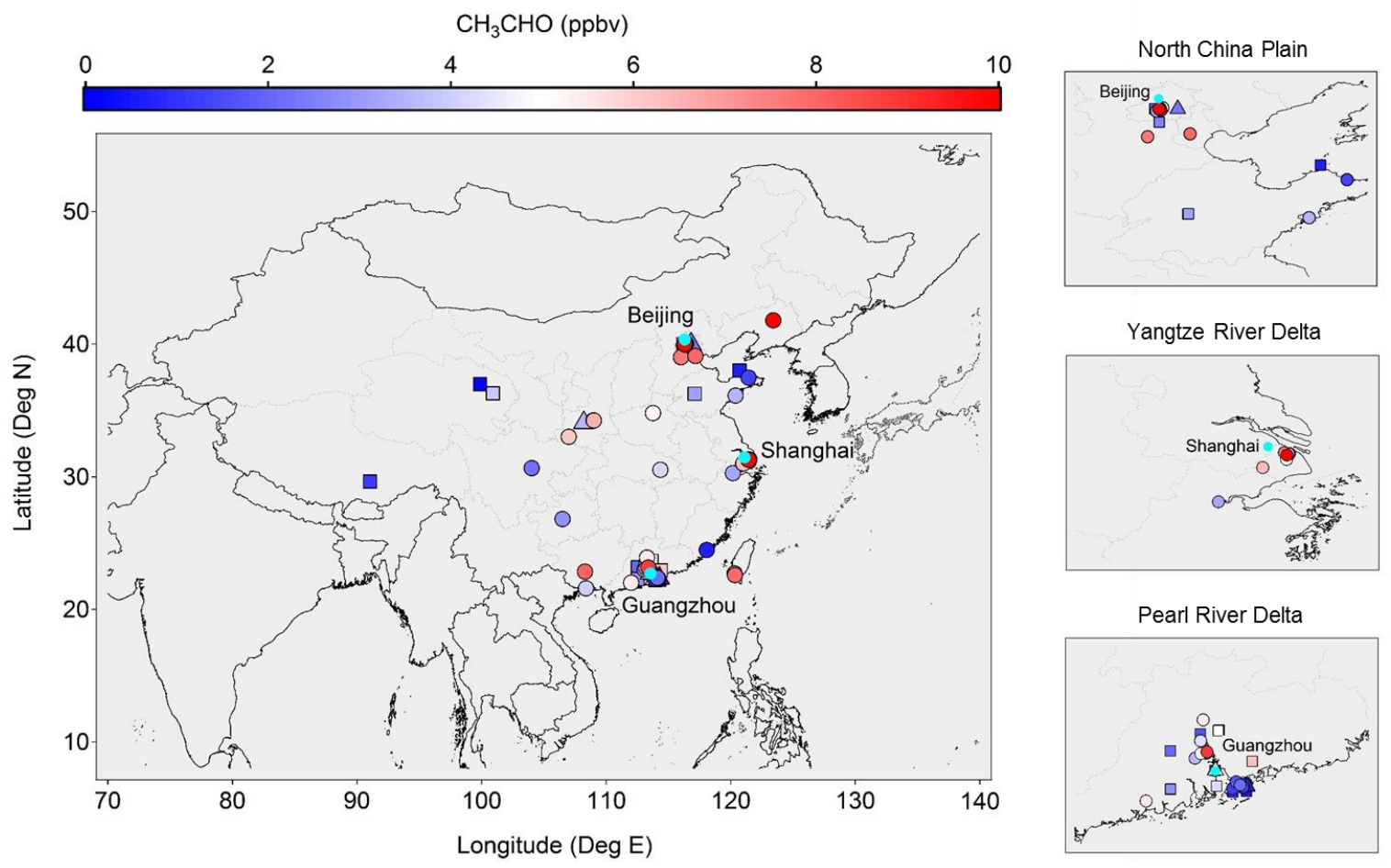

Figure 2b. The same to Figure $2 \mathrm{a}$ but for $\mathrm{CH}_{3} \mathrm{CHO}$. 

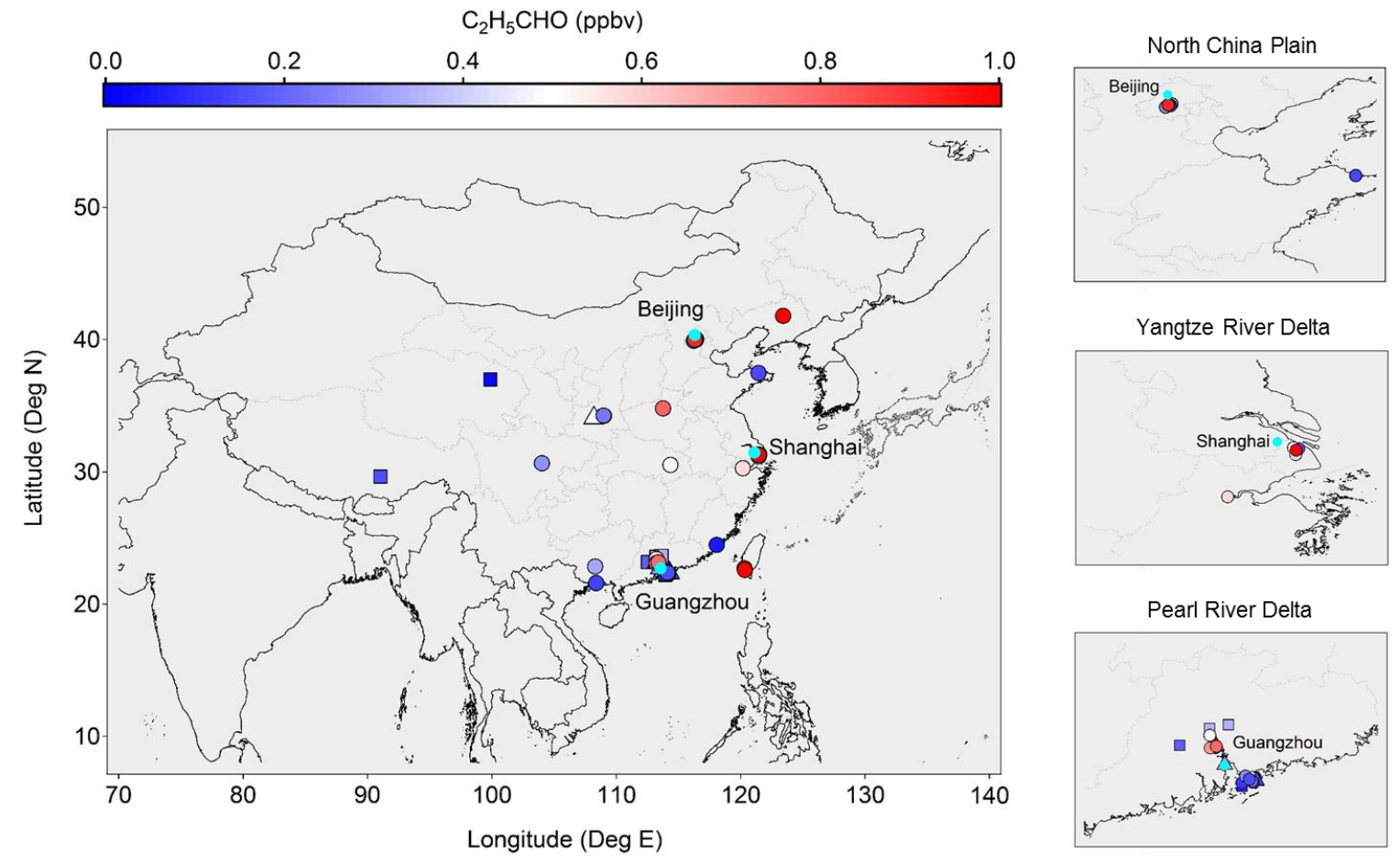

Figure 2c. The same to Figure $2 \mathrm{a}$ but for $\mathrm{C}_{2} \mathrm{H}_{5} \mathrm{CHO}$.
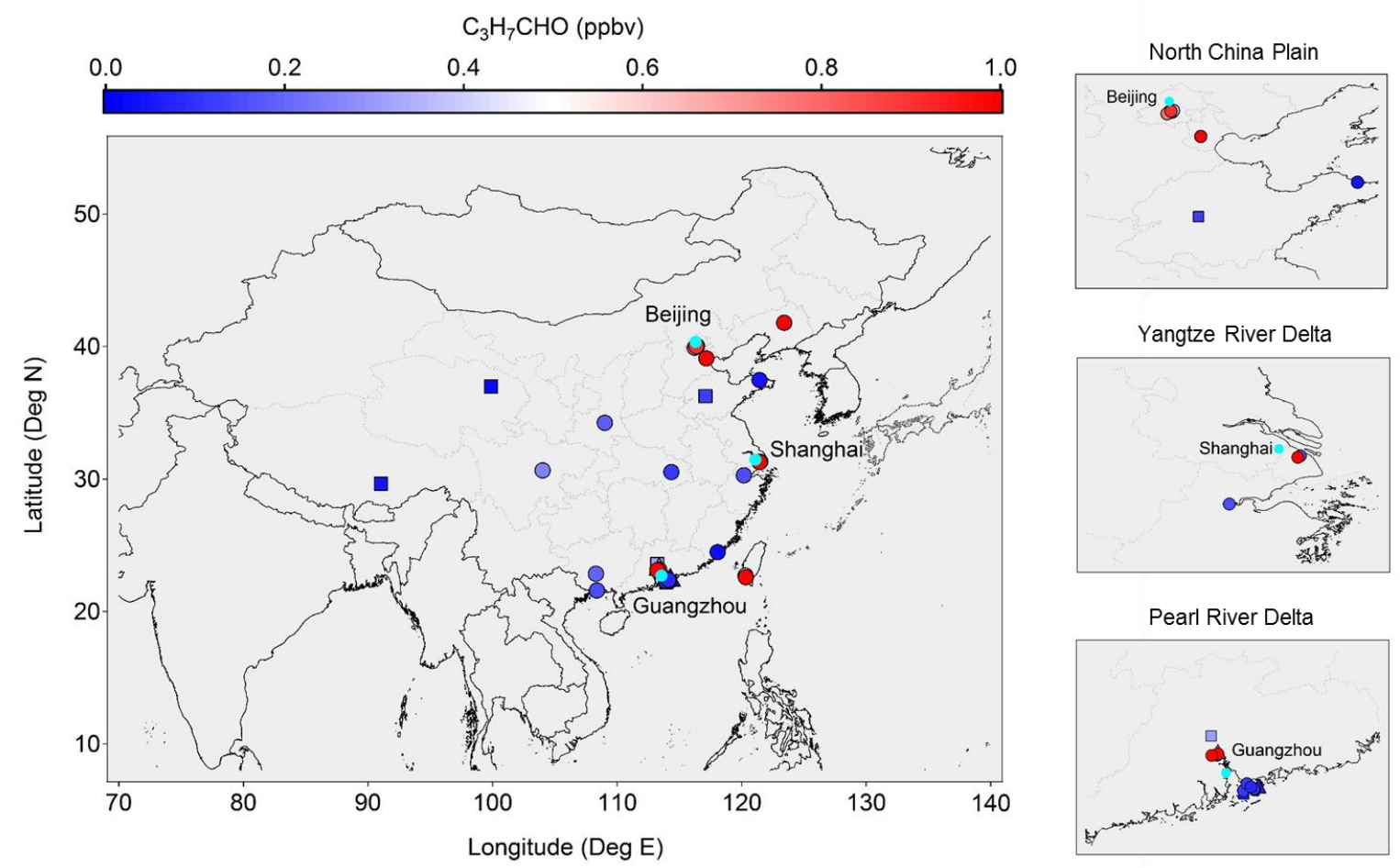

Figure 2d. The same to Figure $2 \mathrm{a}$ but for $\mathrm{C}_{3} \mathrm{H}_{7} \mathrm{CHO}$. 


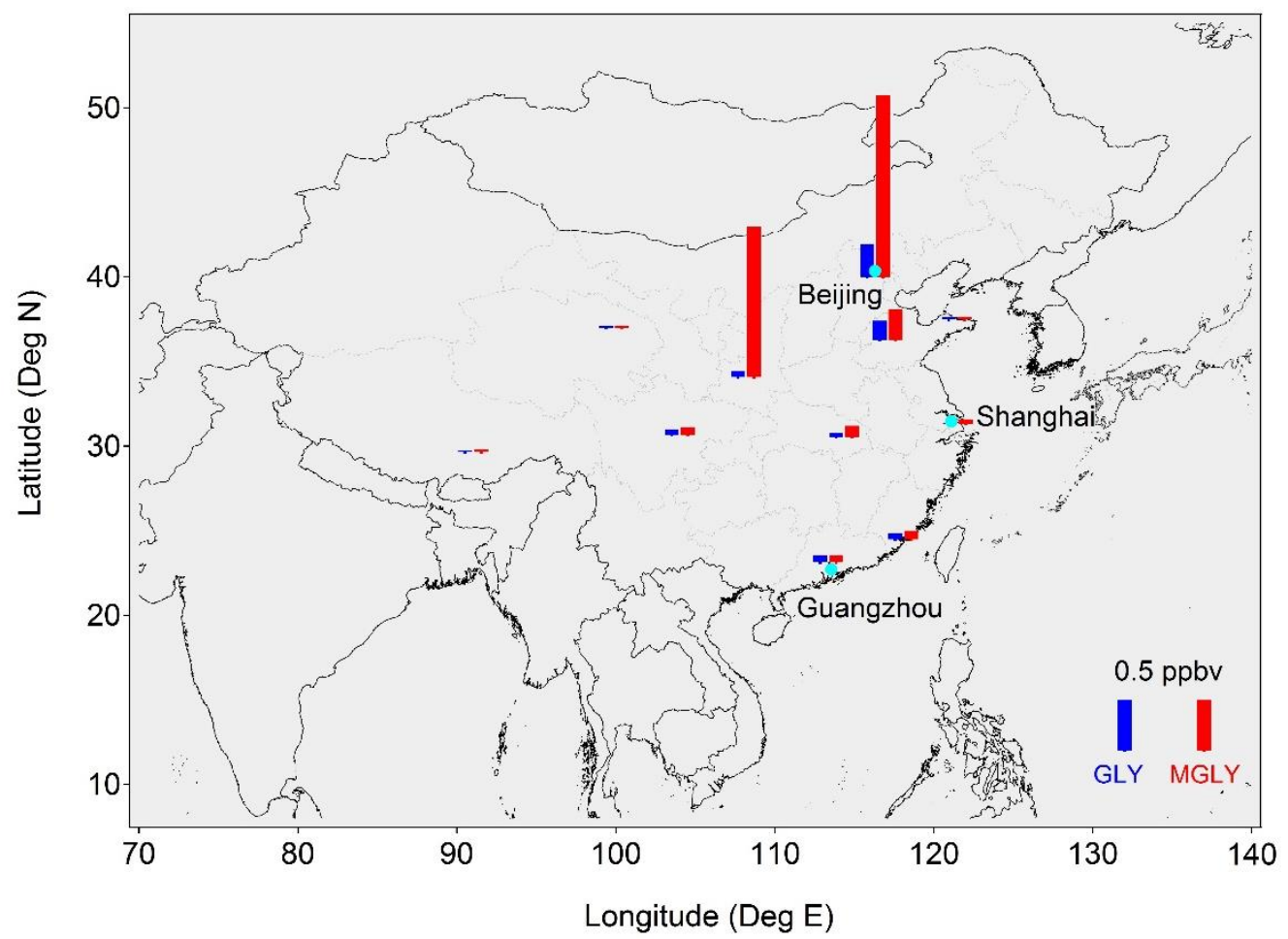

1029

Figure 3a. Spatial distributions of GLY and MGLY levels (ppbv) in China in summer. The 1031 observation data are taken from Ho et al. (2014a), Ho et al. (2015), Kawamura et al. (2013), 1032 Lui et al. (2017a), and Rao et al. (2016).

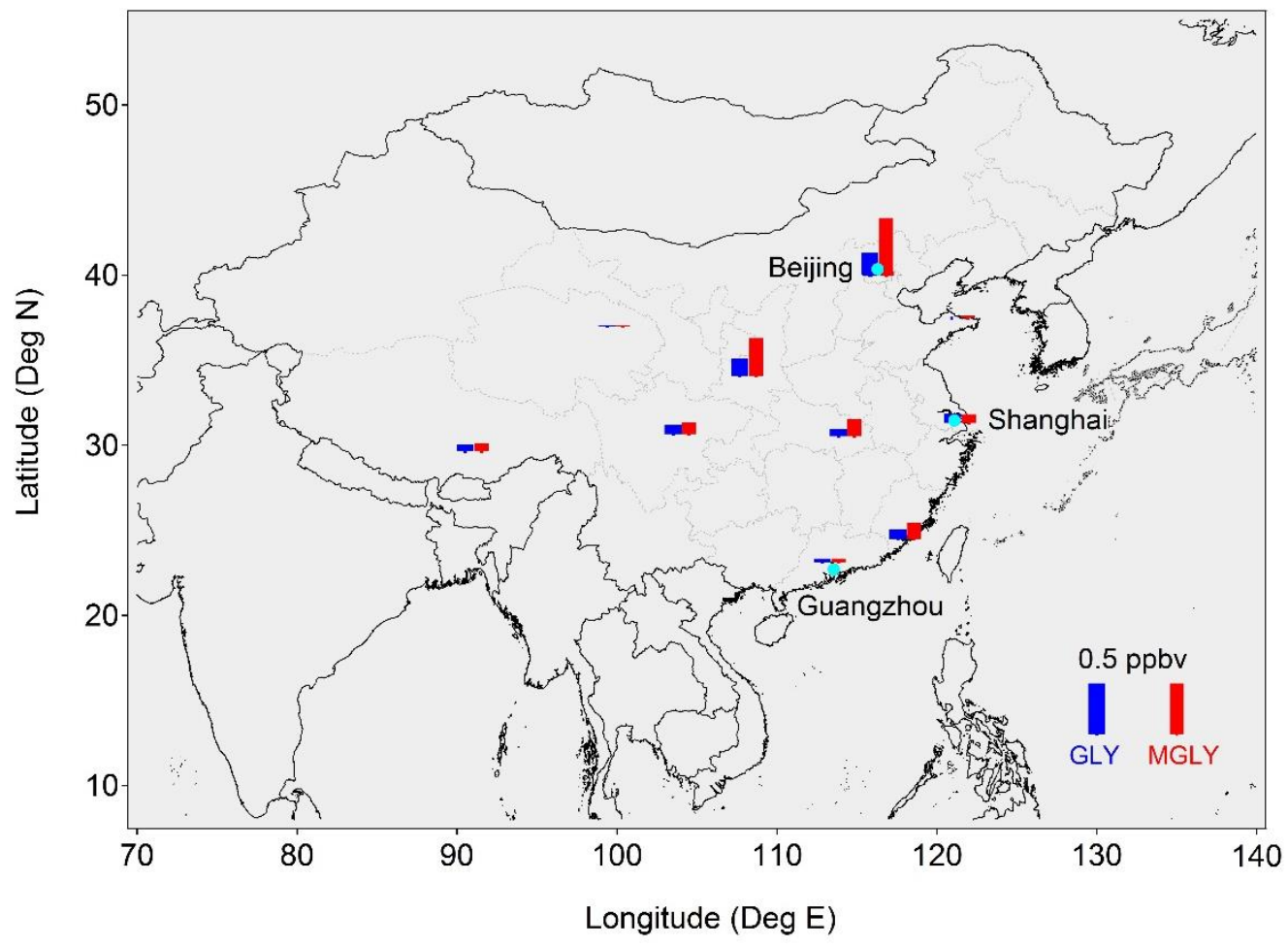

Figure 3b. The same to Figure 3 a but for data in winter. 

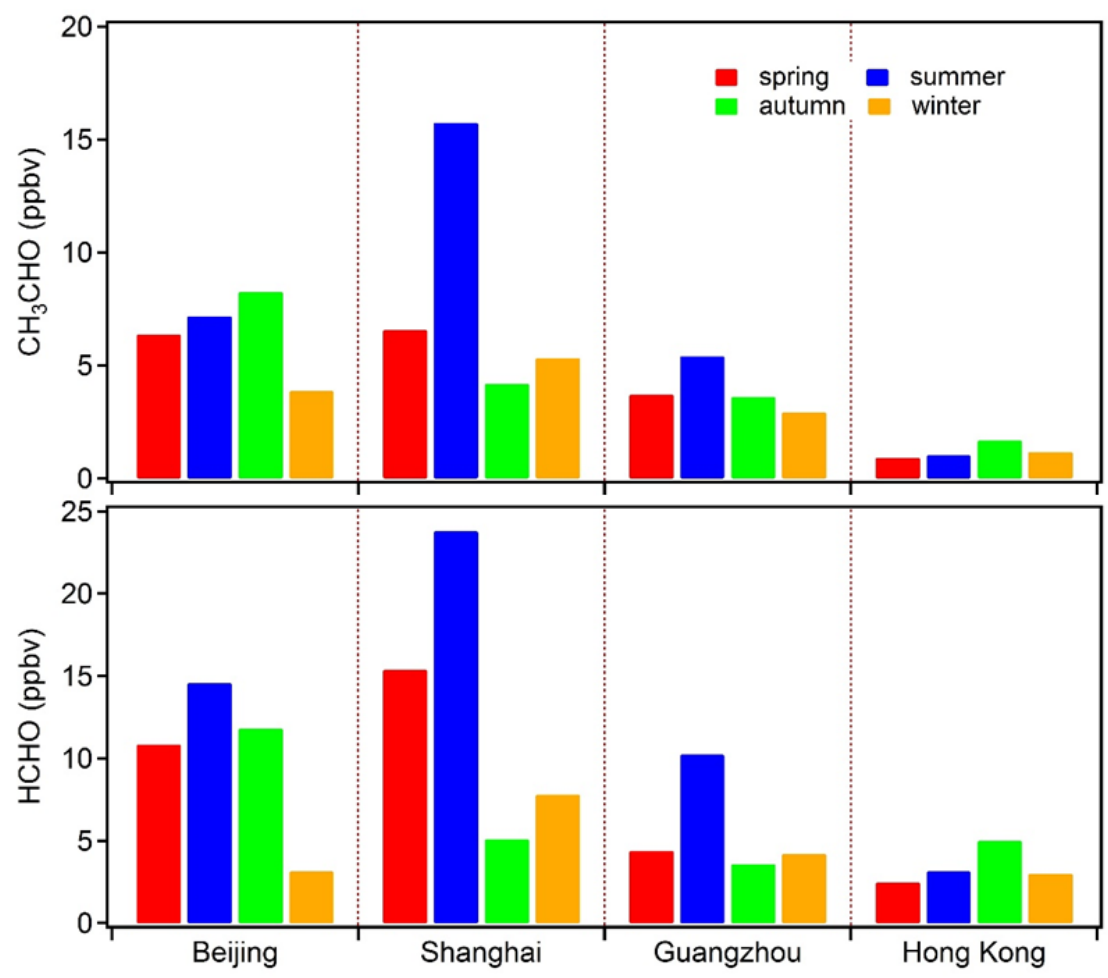

Figure 4. Seasonal variations of $\mathrm{HCHO}$ and $\mathrm{CH}_{3} \mathrm{CHO}$ in Beijing, Shanghai, Guangzhou, and Hong Kong, respectively. The observation data are taken from Huang et al. (2008), Lü et al. (2010), Lui et al. (2017c), and Pang and Mu (2006). 
Table 1. Summary of basic information of major carbonyl species that have ever been observed in China.

\begin{tabular}{|c|c|c|c|c|}
\hline Species & Molecular formula & $\mathrm{J}\left(\mathrm{s}^{-1}\right)$ & Methods available & $\mathrm{K}_{\mathrm{OH}}\left(\times 10^{-12} \mathrm{~cm}^{3}\right.$ molecule $\left.\mathrm{s}^{-1}\right)$ \\
\hline Formaldehyde & $\mathrm{HCHO}$ & $9.02 \times 10^{-5}$ & $\begin{array}{c}\text { Offline: DNPH-HPLC, PFPH-TD-GC/MS; } \\
\text { Online: PTR-MS, PTR-TOF-MS, PTR-ID- } \\
\text { CIMS, LP-DOAS, MAX-DOAS; }\end{array}$ & 8.5 \\
\hline Acetaldehyde & $\mathrm{CH}_{3} \mathrm{CHO}$ & $7.31 \times 10^{-6}$ & $\begin{array}{l}\text { Offline: DNPH-HPLC, PFPH-TD-GC/MS; } \\
\text { Online: PTR-MS, PTR-TOF-CIMS, PTR-TOF- } \\
\text { MS; }\end{array}$ & 15.3 \\
\hline Acetone & $\mathrm{CH}_{3} \mathrm{COCH}_{3}$ & - & $\begin{array}{l}\text { Offline: DNPH-HPLC; } \\
\text { Online: GC-MS/FID, PTR-MS, PTR-TOF- } \\
\text { CIMS, PTR-TOF-MS; }\end{array}$ & 0.18 \\
\hline Acrolein & $\mathrm{CH}_{2} \mathrm{CHCHO}$ & $1.42 \times 10^{-6}$ & $\begin{array}{l}\text { Offline: DNPH-HPLC; } \\
\text { Online: GC-MS/FID, PTR-MS; }\end{array}$ & 21.6 \\
\hline Propionaldehyde & $\mathrm{C}_{2} \mathrm{H}_{5} \mathrm{CHO}$ & $1.18 \times 10^{-5}$ & $\begin{array}{l}\text { Offline: DNPH-HPLC, PFPH-TD-GC/MS; } \\
\text { Online: GC-MS/FID; }\end{array}$ & 18.7 \\
\hline Crotonaldehyde & $\mathrm{CH}_{3} \mathrm{CHCHCHO}$ & $6.61 \times 10^{-6}$ & $\begin{array}{l}\text { Offline: DNPH-HPLC; } \\
\text { Online: GC-MS/FID, PTR-MS; }\end{array}$ & 36 \\
\hline Methacrolein & $\mathrm{CH}_{2} \mathrm{C}\left(\mathrm{CH}_{3}\right) \mathrm{CHO}$ & - & $\begin{array}{l}\text { Offline: DNPH-HPLC; } \\
\text { Online: GC-MS/FID, PTR-MS; }\end{array}$ & 32 \\
\hline Methyl ethyl ketone & $\mathrm{CH}_{3} \mathrm{COC}_{2} \mathrm{H}_{5}$ & - & $\begin{array}{l}\text { Offline: DNPH-HPLC; } \\
\text { Online: GC-MS/FID, PTR-MS, PTR-TOF- } \\
\text { CIMS, PTR-TOF-MS; }\end{array}$ & 1.1 \\
\hline Butyraldehyde & $\mathrm{C}_{3} \mathrm{H}_{7} \mathrm{CHO}$ & $1.98 \times 10^{-5}$ & $\begin{array}{l}\text { Offline: DNPH-HPLC, PFPH-TD-GC/MS; } \\
\text { Online: GC-MS/FID; }\end{array}$ & 23.7 \\
\hline Benzaldehyde & $\mathrm{C}_{6} \mathrm{H}_{5} \mathrm{CHO}$ & $3.12 \times 10^{-4}$ & Offline: DNPH-HPLC, PFPH-TD-GC/MS; & 12.6 \\
\hline Pentanal & $\mathrm{C}_{4} \mathrm{H}_{9} \mathrm{CHO}$ & $1.80 \times 10^{-5}$ & $\begin{array}{l}\text { Offline: DNPH-HPLC; } \\
\text { Online: PTR-MS; }\end{array}$ & 26.6 \\
\hline m-Tolualdehyde & $\mathrm{CH}_{3} \mathrm{C}_{6} \mathrm{H}_{4} \mathrm{CHO}$ & - & Offline: DNPH-HPLC; & 16.8 \\
\hline Hexaldehyde & $\mathrm{C}_{5} \mathrm{H}_{11} \mathrm{CHO}$ & $2.41 \times 10^{-5}$ & Offline: DNPH-HPLC; & 28.5 \\
\hline
\end{tabular}




\begin{tabular}{ccclc} 
Cyclohexanone & $\mathrm{C}_{6} \mathrm{H}_{10} \mathrm{O}$ & - & Offline: DNPH-HPLC; & 6.4 \\
p-Tolualdehyde & $\mathrm{CH}_{3} \mathrm{C}_{6} \mathrm{H}_{4} \mathrm{CHO}$ & - & Offline: DNPH-HPLC; & 16.8 \\
o-Tolualdehyde & $\mathrm{CH}_{3} \mathrm{C}_{6} \mathrm{H}_{4} \mathrm{CHO}$ & $2 \times 10^{-4}$ & Offline: DNPH-HPLC; & 18.9 \\
2,5-Dimethyl-benzaldehyde & $\left(\mathrm{CH}_{3}\right)_{2} \mathrm{C}_{6} \mathrm{H}_{3} \mathrm{CHO}$ & - & Offline: DNPH-HPLC; & 31.5 \\
Heptaldehyde & $\mathrm{C}_{6} \mathrm{H}_{13} \mathrm{CHO}$ & $1.13 \times 10^{-5}$ & Offline: DNPH-HPLC, PFPH-TD-GC/MS; & 29.6 \\
Octylaldehyde & $\mathrm{C}_{8} \mathrm{H}_{16} \mathrm{O}$ & - & Offline: DNPH-HPLC, PFPH-TD-GC/MS; & 30 \\
Nonanaldehyde & $\mathrm{C}_{9} \mathrm{H}_{18} \mathrm{O}$ & - & Offline: DNPH-HPLC; & 32 \\
Decylaldehyde & $\mathrm{C}_{10} \mathrm{H}_{20} \mathrm{O}$ & - & Offline: DNPH-HPLC; & 30 \\
Undecanal & $\mathrm{C}_{11} \mathrm{H}_{22} \mathrm{O}$ & - & Offline: DNPH-HPLC; & - \\
& & & Offline: DNPH-HPLC; & 3.9 \\
Methyl vinyl ketone & $\mathrm{CH}_{3} \mathrm{COCHCH}_{2}$ & - & Online: GC-MS/FID, PTR-TOF-CIMS, PTR- & MS; \\
Glyoxal & & & Offline: DNPH-HPLC, PFPH-TD-GC/MS; & 9 \\
Methylglyoxal & $\mathrm{CHOCHO}^{2}$ & $1.40 \times 10^{-4}$ & Online: MAX-DOAS; & 13 \\
\hline
\end{tabular}

The $k_{\mathrm{OH}}$ values were under conditions of $298 \mathrm{~K}$ and 1 bar; the $k_{\mathrm{OH}}$ values and photolysis frequencies are taken from Calvert et al. (2011) and Mellouki et al. (2015). 
Table 2. Summary of studies of radical source and $\mathrm{OH}$ reactivity in China.

\begin{tabular}{|c|c|c|c|c|c|c|c|}
\hline Site & Measurement period & Type & $\begin{array}{l}\text { Dominant primary } \\
\text { source of } \mathrm{OH}\end{array}$ & $\begin{array}{c}\text { Dominant } \\
\text { contributor to } \mathrm{OH} \\
\text { reactivity }\end{array}$ & $\begin{array}{l}\text { Dominant primary } \\
\text { source of } \mathrm{HO}_{2}\end{array}$ & $\begin{array}{l}\text { Dominant primary } \\
\text { source of } \mathrm{RO}_{2}\end{array}$ & Reference \\
\hline${ }^{\mathrm{a} C R A E S}$, Beijing & Jul.-Aug. 2008 & Urban & $\mathrm{O}_{3}$ photolysis & OVOCs & OVOCs photolysis & OVOCs photolysis & Yang et al. (2018) \\
\hline \multirow[t]{3}{*}{${ }^{\text {aPKU, Beijing }}$} & Aug. 2005 & Urban & - & Alkenes & - & - & Shao et al. (2009) \\
\hline & Aug. 2006 & Urban & - & OVOCs & - & - & Shao et al. (2009) \\
\hline & Aug. 2007 & Urban & HONO photolysis & - & OVOCs photolysis & OVOCs photolysis & Liu et al. (2012a) \\
\hline Yufa, Beijing & Aug. 2006 & Rural & - & Alkenes, OVOCs & - & - & Shao et al. (2009) \\
\hline Mazhuang, Tai'an & Jul. 2007 & Rural & $\mathrm{O}_{3}$ photolysis & - & - & - & Wang et al. (2010b) \\
\hline Wangdu, Hebei & Jun.-Jul. 2014 & Rural & - & OVOCs & - & - & Fuchs et al. (2017) \\
\hline${ }^{\mathrm{a}}$ FDU, Shanghai & Apr.-Aug. 2013 & Urban & HONO photolysis & - & - & - & Nan et al. (2017) \\
\hline Baiyunshan, Guangzhou & Jul. 2006 & Urban & - & Alkenes & - & - & Yuan et al. (2012a) \\
\hline Huijingcheng, Foshan & Jul. 2006 & Urban & - & Alkenes & - & - & Yuan et al. (2012a) \\
\hline Wanqingsha, Guangzhou & Jul. 2006 & Suburban & - & OVOCs & - & - & Yuan et al. (2012a) \\
\hline Tangjia, Zhuihai & Jul. 2006 & Rural & - & Isoprene & - & - & Yuan et al. (2012a) \\
\hline Tianhu, Guangzhou & Oct.-Nov. 2008 & Rural & - & OVOCs & - & - & Yuan et al. (2012a) \\
\hline Jinguowan, Huizhou & Jul. 2006 & Rural & - & OVOCs & - & - & Yuan et al. (2012a) \\
\hline Jaingmen & Oct.-Nov. 2008 & Rural & - & OVOCs & - & - & Yuan et al. (2012a) \\
\hline
\end{tabular}




\begin{tabular}{|c|c|c|c|c|c|c|c|}
\hline Hok Tsui, Hongkong & 2012 & Rural & $\mathrm{O}_{3}$ photolysis & OVOCs & OVOCs photolysis & OVOCs photolysis & Li et al. (2018) \\
\hline Tung Chung, Hongkong & Aug. 2011 & Suburban & HONO photolysis & OVOCs & OVOCs photolysis & OVOCs photolysis & Xue et al. (2016) \\
\hline Shenzhen & Summer, 2016 & Urban & HONO photolysis & - & - & - & Wang et al. (2017a) \\
\hline Chengdu & Sep.-Oct. 2016 & Suburban & - & Alkenes & - & - & Tan et al. (2018) \\
\hline Lanzhou & Jun.-Aug. 2013 & Urban & $\mathrm{O}_{3}$ photolysis & - & HCHO photolysis & OVOCs photolysis & Jia et al. (2018) \\
\hline Lanzhou & Jun.-Aug. 2013 & Industrial & $\mathrm{O}_{3}$ photolysis & - & HCHO photolysis & OVOCs photolysis & Jia et al. (2018) \\
\hline Mt. Waliguan & Apr.-May and Jul.-Aug. 2003 & Mountain & $\mathrm{O}_{3}$ photolysis & - & HCHO photolysis & OVOCs photolysis & Xue et al. (2013) \\
\hline
\end{tabular}

${ }^{a}$ CRAES: Chinese Research Academy of Environmental Sciences; PKU: Peking University; FDU: Fudan University; 